\title{
Design, Synthesis and In Vitro Cytotoxic Activity of New 6,9-Disubstituted Purine Analogues
}

\author{
Asligul Kucukdumlu, ${ }^{1}$ Meral Tuncbilek, ${ }^{1, *}$ Ebru Bilget Guven ${ }^{2}$ \\ and Rengul Cetin Atalay ${ }^{3}$ \\ ${ }^{1}$ Department of Pharmaceutical Chemistry, Faculty of Pharmacy, Ankara University, 06100 Ankara, Turkey \\ ${ }^{2}$ Department of Bioinformatics and Genetics, Faculty of Engineering and Natural Sciences, Kadir Has University, \\ 34083, Cibali-Fatih, Istanbul, Turkey \\ ${ }^{3}$ Department of Bioinformatics, Graduate School of Informatics, Middle East Technical University, 06800 Ankara, Turkey \\ *Corresponding author: E-mail: tuncbile@pharmacy.ankara.edu.tr
}

Received: 04-12-2019

\begin{abstract}
A series of new 6,9-disubstituted purine analogs with 4-substituted piperazine at C-6 and 4-substituted benzyl at N-9 were designed and synthesized in four steps. All synthesized compounds (7-26) were screened initially for their in vitro anticancer activity on Huh7 liver, HCT116 colon and MCF7 breast carcinoma cell lines. Cytotoxic bioactivity studies revealed that all compounds screened, with compound 19 being the exception, were found to have promising cytotoxic activities at $\mathrm{IC}_{50}$ range of $0.05-21.8 \mu \mathrm{M}$ against cancer cells Huh7, HCT116 and MCF7. Among the prepared purine analogs, two of them (12 and 22) exhibited excellent cytotoxic activities, with $\mathrm{IC}_{50} 0.08-0.13 \mu \mathrm{M}$, on Huh7 cells comparable to camptothecin (CPT) and better than cladribine, fludarabine and 5-FU. Afterwards, the evaluation of cytotoxicity of the most potent purine analogs was screened against further hepatocellular cancer (HCC) cell lines. The 6-(4-(4-trifluoromethylphenyl)piperazine (12) and 6-(4-(3,4-dichlorophenyl)piperazine analogs (25) displayed a significant $\mathrm{IC}_{50}$ values $\left(\mathrm{IC}_{50}<0.1-0.13 \mu \mathrm{M}\right)$ comparable to $\mathrm{CPT}$ and better cytotoxic bioactivity when compared with 5-FU, cladribine and fludarabine on HCC cells (Huh7 and HepG2).
\end{abstract}

Keywords: Purine; piperazine; benzyl; cytotoxic activity

\section{Introduction}

The purine nucleus is involved in the biological molecules that play a key role in the signaling pathways of all living organisms. ${ }^{1}$ For this reason, the purine structure is an interesting organic moiety included in new drugs. $\mathrm{Pu}-$ rine and purine nucleoside analogs exhibit a variety of biological activities. These analogs have been extensively studied as enzyme inhibitors, ${ }^{2-5}$ cytotoxic, ${ }^{6-10}$ antiviral, ${ }^{11-14}$ antihyperglycemic, ${ }^{15}$ immunostimulatory, ${ }^{16}$ antifungal, and antibacterial ${ }^{17-22}$ agents due to their potential activities, even though their antiviral and anticancer effects are more commonly known. 5-Fluorouracil (5-FU), a well known fluorinated nucleobase analogue, is highly preferred for the treatment of various cancers in clinics. ${ }^{23}$ Subsequently, other pyrimidine analogs, such as cytarabine, gemcitabine, capecitabine, decitabine, and 5-fluoro deoxyuridine have been used in solid tumors and hematologic malignancies. ${ }^{24-26}$ Purine nucleobase analogs such as 6-mercaptopurine and 6-thioguanine, are specifically used in pediatric acute lymphoblastic leukemia as an inhibitor of nucleic acid metabolism. ${ }^{27,28}$ In addition, many purine nucleoside analogs (fludarabine, cladribine, pentostatin, nelarabine, and clofarabine) are clinically administered in the treatment of solid and hematological malignancies. ${ }^{29-32}$

A large number of investigations indicate that purine nucleobases and purine nucleosides target a series of pathways in chemotherapy-induced cell death mechanisms, such as apoptosis, necrosis, senescence, autophagy, and mitotic catastrophe. ${ }^{25,33-35}$ Also, various purine scaffolds and their analogs have been studied as potential anticancer agents that contain cyclin-dependent kinase and heat shock protein inhibition. Olomoucine, ${ }^{36}$ roscovitine, ${ }^{37}$ purvalanol A, B, amino-purvalanol ${ }^{38}$ (Figure 1) have been synthesized and screened as cyclin-dependent kinase inhibitors. Especially, R-roscovitine is under investigation as 
<smiles>Cn1cnc2c(NCc3ccccc3)nc(NCCO)nc21</smiles>

Olomoucine

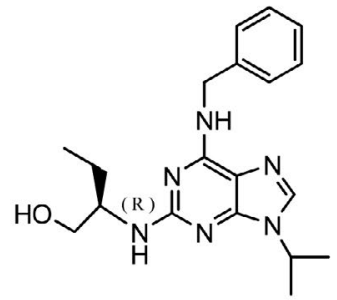

Roscovitine<smiles>[R]c1cc(CNc2nc(NCC(C)C)nc3c2ncn3C(C)C)cc(Cl)c1[R]</smiles>

Purvalanol A $\left(\mathrm{R}_{1}=\mathrm{H}, \mathrm{R}_{2}=\mathrm{H}\right)$

Purvalanol B $\left(\mathrm{R}_{1}=\mathrm{COOH}, \mathrm{R}_{2}=\mathrm{H}\right)$

Amino-Purvalanol $\left(\mathrm{R}_{1}=\mathrm{H}, \mathrm{R}_{2}=\mathrm{NH}_{2}\right)$

Figure 1. Structures of olomoucine, roscovitine, purvalanol A, B and amino-purvalanol

a chemotherapeutic agent against non-small cell lung cancer and other malignancies. Also, olomoucine with its 2,6,9-trisubstitued purine structure is another purine derivative with antiproliferative effects on cancer cell lines.

In addition to this, various heterocyclic analogs of purines, such as imidazo-pyrazines, ${ }^{39}$ pyrazolo-pyridazines, ${ }^{40}$ imidazo-pyridines, ${ }^{41,42}$ thieno-pyridines, ${ }^{43}$ pyrrolo-pyrimidines, ${ }^{44}$ pyrazolo-pyrimidines, ${ }^{45,46}$ thieno-pyrimidines ${ }^{47}$ and triazolo-pyrimidines ${ }^{48,49}$ have been found to possess anticancer activities.

The heat shock protein 90 (Hsp90) has been an existing target in cancer since its inhibition may lead to the

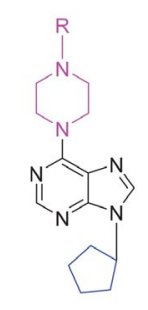

A

${ }_{I C} C_{50}=0.1-0.3 \mu \mathrm{M}$

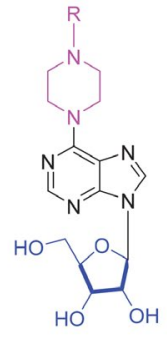

B

$\mathrm{IC}_{50}=5.2-9.2 \mu \mathrm{M}$

$\mathrm{R}=\mathrm{Ph}-4-\mathrm{CF}_{3}$

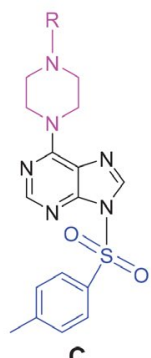

$I_{50}=1.0-1.4 \mu \mathrm{M}$ $\downarrow$

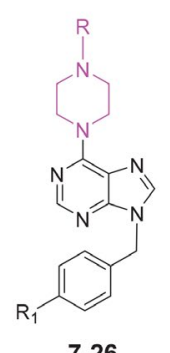

Target purine compounds for this work

Figure 2. Structures of 9-(cyclopentyl/ $\beta$-D-ribofuranosyl/para-toluenesulfonyl)-6-(4-substituted piperazino)purine analogs A, B, C and target purine compounds 7-26. breakdown of many cancer-associated proteins. Furthermore, inhibitors of Hsp90 kill cancer cells at lower concentrations than is required to harm normal human cells. In recent years, purine analogues, which are Hsp90 inhibitors, have entered clinical trials as drugs in the therapy of solid tumors and hematologic malignancies. ${ }^{50}$

In our previous studies, ${ }^{51,52}$ we have reported important cytotoxic activities of 9-(cyclopentyl/ $\beta$-D-ribofuranosyl/para-toluenesulfonyl)-6-(4-substituted piperazino)purine analogs A, B, C (Figure 2). In this work, we report the synthesis of new analogs of purines $A, B, C$ as 9-(4-substituted benzyl)purines and evaluate their cytotoxic activities against liver (Huh7), colon (HCT116) and and breast (T47D) carcinoma cell lines. We further investigate the most active compounds $(\mathbf{7 - 1 8}, 20,22-26)$ on a panel of liver cancer cells.

\section{Experimental}

\section{1. Chemistry}

Melting points were recorded with a capillary melting point apparatus (Electrothermal 9100) and are uncorrected. NMR spectra were recorded on a VARIAN Mercury 400 FT-NMR spectrometer $\left(400 \mathrm{MHz}\right.$ for ${ }^{1} \mathrm{H}, 100.6 \mathrm{MHz}$ for $\left.{ }^{13} \mathrm{C}\right)$. TMS was used as internal standard for the ${ }^{1} \mathrm{H}$ NMR and ${ }^{13} \mathrm{C}$ NMR spectra; values are given in $\delta$ (ppm) and $J$ values are in Hz. Mass spectra were taken on Waters Micromass ZQ by using the ESI+ method. Elemental analyses (C, $\mathrm{H}, \mathrm{N}$ ) were determined on a Leco CHNS 932 instrument and gave values within $\pm 0.4 \%$ of the theoretical values. Column chromatography was accomplished on silica gel 60 (0.040-0.063 mm particle size). The chemical reagents used in the synthesis were purchased from Merck, Fluka, Sigma and Aldrich. 5-Amino-4,6-dichloropyrimidine (2) was synthesized according to the reported method. ${ }^{53}$

\section{1. 1. General Procedure for the Synthesis of Compounds 3 and 4}

5-Amino-4,6-dichloropyrimidine (2) (1 mmol) was dissolved in $5 \mathrm{~mL}$ of absolute $\mathrm{EtOH}$, and then 4-substitut- 
ed benzylamines $(2 \mathrm{mmol})$ and $\mathrm{Et}_{3} \mathrm{~N}(3 \mathrm{mmol})$ were added. The mixture was refluxed for $15 \mathrm{~h}$. The reaction mixture was concentrated in vacuo, and the residue was purified by column chromatography (EtOAC-hexane, 1:4 to $1: 2$ ).

\section{1. 1. 1. 5-Amino-6-chloro-4-[(4-} trifluoromethylbenzyl)amino]pyrimidine (3)

Yield $120 \mathrm{mg}$ (65\%), m.p. $181-183{ }^{\circ} \mathrm{C} .{ }^{1} \mathrm{H}$ NMR $\left(\mathrm{CDCl}_{3}\right) \delta 3.40(\mathrm{br} \mathrm{s}, 2 \mathrm{H}), 4.77(\mathrm{~d}, 2 \mathrm{H}, J=5.6 \mathrm{~Hz}), 5.24(\mathrm{~s}$, $1 \mathrm{H}), 7.46(\mathrm{~d}, 2 \mathrm{H}, J=8 \mathrm{~Hz}), 7.60(\mathrm{~d}, 2 \mathrm{H}, J=8 \mathrm{~Hz}), 8.11(\mathrm{~s}$, 1H). MS (ESI+) $m / z: 303.34(100 \%)(\mathrm{M}+\mathrm{H}), 305.35(40 \%)$ $(\mathrm{M}+\mathrm{H}+2)$. Anal. Calcd for $\mathrm{C}_{12} \mathrm{H}_{10} \mathrm{ClF}_{3} \mathrm{~N}_{4}: \mathrm{C}, 47.62 ; \mathrm{H}$, 3.33; N, 18.51. Found: C, 47.63; H, 3.41; N, 18.45.

\section{1. 1. 2. 5-Amino-6-chloro-4-[(4-chlorobenzyl)amino] pyrimidine (4)}

Yield $140 \mathrm{mg}$ (88\%), m.p. $192-194{ }^{\circ} \mathrm{C} .{ }^{1} \mathrm{H}$ NMR $\left(\mathrm{DMSO}-d_{6}\right) \delta 4.58(\mathrm{~d}, 2 \mathrm{H}, J=5.6 \mathrm{~Hz}), 5.07(\mathrm{~s}, 2 \mathrm{H}), 7.28-$ $7.40(\mathrm{~m}, 5 \mathrm{H}), 7.70(\mathrm{~s}, 1 \mathrm{H})$. MS (ESI+) $\mathrm{m} / z: 269.24(100 \%)$ $\left(\mathrm{M}^{+}\right), 271.24(55 \%)(\mathrm{M}+2)$. Anal. Calcd for $\mathrm{C}_{11} \mathrm{H}_{10} \mathrm{Cl}_{2} \mathrm{~N}_{4}$ : C, 49.09; H, 3.75; N, 20.82. Found: C, 49.14; H, 3.66; N, 20.42 .

\section{1. 2. General Procedure for the Synthesis of Compounds 5 and 6}

A mixture of 5-amino-6-chloro-4-[(4-substitutedbenzyl)amino]pyrimidines $(3,4)(0.29 \mathrm{mmol}), 2 \mathrm{~mL}$ triethyorthoformate and para-toluenesulfonic acid (0.03 $\mathrm{mmol}$ ) was stirred at room temperature for $72 \mathrm{~h}$. The residue was dissolved with $\mathrm{CH}_{2} \mathrm{Cl}_{2}$, washed with saturated $\mathrm{NaHCO}_{3}$ and brine. The extract was dried over $\mathrm{Na}_{2} \mathrm{SO}_{4}$, the solvent was evaporated in vacuo, and the residue was purified by column chromatography (EtOAC-hexane, 1:4 to $1: 2$ ).

\section{1. 2. 1. 6-Chloro-9-(4-trifluoromethylbenzyl)-9H- purine (5)}

Yield $50 \mathrm{mg}$ (51\%), m.p. $131{ }^{\circ} \mathrm{C}$ [Lit. $130-132{ }^{\circ} \mathrm{C}^{54}$ ]. MS (ESI+) $m / z: 313.34(100 \%)(\mathrm{M}+\mathrm{H}), 315.36(47 \%)$ $(\mathrm{M}+\mathrm{H}+2)$.

\section{1. 2. 2. 6-Chloro-9-(4-chlorobenzyl)-9H-purine (6) \\ Yield $240 \mathrm{mg}(87 \%)$, m.p. $133^{\circ} \mathrm{C}$ [Lit. $130-133^{\circ} \mathrm{C}^{54}$ ]. MS (ESI+) $m / z: 279.27(100 \%)\left(\mathrm{M}^{+}\right), 281.27(63 \%)(\mathrm{M}+2)$. \\ 2. 1. 3. General Procedure for the Synthesis of the Final Compounds 7-26}

The appropriate 1-substituted piperazines $(1 \mathrm{mmol})$ and $\mathrm{Et}_{3} \mathrm{~N}(3 \mathrm{mmol})$ were added to a solution of 6-chloropurines $(1 \mathrm{mmol})(\mathbf{5}, \mathbf{6})$ in $5 \mathrm{~mL}$ of absolute $\mathrm{EtOH}$. The mixture was refluxed for $8-16 \mathrm{~h}$. The reaction mixture was concentrated in vacuo and the residue was purified by column chromatography (EtOAC-hexane, 1:3 to 1:1).
2. 1. 3. 1. 6-[4-(2-Hydroxyethyl)piperazine-1-yl]-9-(4trifluoromethylbenzyl)-9H-purine (7)

Yield $270 \mathrm{mg}$ (65\%), m.p. $141-143{ }^{\circ} \mathrm{C} .{ }^{1} \mathrm{H}$ NMR $\left(\mathrm{CDCl}_{3}\right) \delta 2.61(\mathrm{t}, 2 \mathrm{H}, J=5.6 \mathrm{~Hz}), 2.66(\mathrm{t}, 4 \mathrm{H}, J=5.2 \mathrm{~Hz})$, $3.68(\mathrm{t}, 2 \mathrm{H}, J=4.8 \mathrm{~Hz}), 4.34(\mathrm{br} \mathrm{s}, 4 \mathrm{H}), 5.43(\mathrm{~s}, 2 \mathrm{H}), 7.36(\mathrm{~d}$, $2 \mathrm{H}, J=8 \mathrm{~Hz}), 7.59(\mathrm{~d}, 2 \mathrm{H}, J=8 \mathrm{~Hz}), 7.74(\mathrm{~s}, 1 \mathrm{H}), 8.37(\mathrm{~s}$, $1 \mathrm{H}) .{ }^{13} \mathrm{C} \mathrm{NMR}\left(\mathrm{CDCl}_{3}\right) \delta 45.12\left(\mathrm{CH}_{2}\right.$ in piperazine), 46.44 $\left(\mathrm{CH}_{2}\right), 53.01\left(\mathrm{CH}_{2}\right.$ in piperazine $), 57.77\left(\mathrm{CH}_{2}-\mathrm{N}\right), 59.45$ $\left(\mathrm{CH}_{2}-\mathrm{OH}\right), 119.77,122.46,125.16$ (C in phenyl), 125.97 $\left(\mathrm{q}, J_{C F}=3.9 \mathrm{~Hz}\right), 127.75,130.57\left(\mathrm{q}, J_{C F}=32.9 \mathrm{~Hz}\right), 137.96$ (C-5), 139.78 (C-8), 151.01 (C-6), 152.79 (C-2), 153.87 (C-4). MS (ESI+) $m / z: 407.65(100 \%)(\mathrm{M}+\mathrm{H})$. Anal. Calcd for $\mathrm{C}_{19} \mathrm{H}_{21} \mathrm{~F}_{3} \mathrm{~N}_{6} \mathrm{O} \cdot 0.3 \mathrm{CH}_{2} \mathrm{Cl}_{2}: \mathrm{C}, 53.67 ; \mathrm{H}, 5.04 ; \mathrm{N}, 19.46$. Found: C, 53.96; $\mathrm{H}, 5.08 ; \mathrm{N}, 19.40$.

\section{1. 3. 2. 6-[4-Cyclohexylpiperazine-1-yl]-9-(4- trifluoromethylbenzyl)-9H-purine (8)}

Yield $360 \mathrm{mg}$ (82\%), m.p. $149-148{ }^{\circ} \mathrm{C} .{ }^{1} \mathrm{H}$ NMR $\left(\mathrm{CDCl}_{3}\right) \delta 1.12-1.89(\mathrm{~m}, 10 \mathrm{H}), 2.33(\mathrm{br} \mathrm{s}, 1 \mathrm{H}), 2.72(\mathrm{t}, 4 \mathrm{H}$, $J=5.2 \mathrm{~Hz}$ ), 4.32 (br s, $4 \mathrm{H}), 5.43(\mathrm{~s}, 2 \mathrm{H}), 7.36(\mathrm{~d}, 2 \mathrm{H}, J=7.6$ $\mathrm{Hz}), 7.59(\mathrm{~d}, 2 \mathrm{H}, J=8.4 \mathrm{~Hz}), 7.73(\mathrm{~s}, 1 \mathrm{H}), 8.36(\mathrm{~s}, 1 \mathrm{H}) .{ }^{13} \mathrm{C}$ $\operatorname{NMR}\left(\mathrm{CDCl}_{3}\right) \delta 25.84,26.25,28.86\left(\mathrm{CH}_{2}\right.$ in cyclohexyl), $45.51\left(\mathrm{CH}_{2}\right.$ in piperazine $), 46.41\left(\mathrm{CH}_{2}\right), 49.12\left(\mathrm{CH}_{2}\right.$ in piperazine), 63.71 ( $\mathrm{CH}$ in cyclohexyl), 119.71, 122.46, 125.17 (C in phenyl), $125.95\left(\mathrm{q}, J_{C F}=3.2 \mathrm{~Hz}\right), 127.72,130.53(\mathrm{q}$, $\left.J_{C F}=32.9 \mathrm{~Hz}\right), 137.79(\mathrm{C}-5), 139.85(\mathrm{C}-8), 150.93(\mathrm{C}-6)$, $152.82(\mathrm{C}-2), 153.82$ (C-4). MS (ESI+) $m / z: 445.86(100 \%)$ $(\mathrm{M}+\mathrm{H})$. Anal. Calcd for $\mathrm{C}_{23} \mathrm{H}_{27} \mathrm{~F}_{3} \mathrm{~N}_{6} \cdot 0.05 \mathrm{H}_{2} \mathrm{O}: \mathrm{C}, 62.02 ; \mathrm{H}$, 6.13; N, 18.86. Found: C, 62.06; H, 6.13; N, 18.86 .

\section{1. 3. 3. 6-[4-(Pyrimidine-2-yl)piperazine-1-yl]-9-(4- trifluoromethylbenzyl)-9H-purine (9)}

Yield $380 \mathrm{mg}$ (86\%), m.p. $171-173{ }^{\circ} \mathrm{C} .{ }^{1} \mathrm{H}$ NMR $\left(\mathrm{CDCl}_{3}\right) \delta 3.99(\mathrm{t}, 4 \mathrm{H}, J=5.6 \mathrm{~Hz}), 4.41(\mathrm{br} \mathrm{s}, 4 \mathrm{H}), 5.45(\mathrm{~s}$, $2 \mathrm{H}), 6.54(\mathrm{t}, 1 \mathrm{H}, J=5.2 \mathrm{~Hz}), 7.37(\mathrm{~d}, 2 \mathrm{H}, J=8 \mathrm{~Hz}), 7.60(\mathrm{~d}$, $2 \mathrm{H}, J=8 \mathrm{~Hz}), 7.77(\mathrm{~s}, 1 \mathrm{H}), 8.35(\mathrm{~d}, 2 \mathrm{H}, J=4.4 \mathrm{~Hz}), 8.41(\mathrm{~s}$, $1 \mathrm{H}) .{ }^{13} \mathrm{C}$ NMR $\left(\mathrm{CDCl}_{3}\right) \delta 43.75\left(\mathrm{CH}_{2}\right.$ in piperazine $), 44.99$ $\left(\mathrm{CH}_{2}\right.$ in piperazine), $46.47\left(\mathrm{CH}_{2}\right), 110.24(\mathrm{C}-5$ in pyrimidine), $119.89,122.46,125.16$ (C in phenyl), 125.98 (q, $J_{C F}=$ $3.9 \mathrm{~Hz}), 127.76,130.57\left(\mathrm{q}, J_{C F}=32.3 \mathrm{~Hz}\right), 138.07(\mathrm{C}-5)$, 139.78 (C-8), 151.06 (C-6), 152.80 (C-2), 154.04 (C-4), 157.77 (C-4,6 in pyrimidine), 161.68 (C-2 in pyrimidine). MS (ESI+) $m / z: 441.8(100 \%)(\mathrm{M}+\mathrm{H})$. Anal. Calcd for $\mathrm{C}_{21} \mathrm{H}_{19} \mathrm{~F}_{3} \mathrm{~N}_{8}$ : C, 57.27; $\mathrm{H}, 4.35 ; \mathrm{N}, 25.44$. Found: $\mathrm{C}$, 57.36; $\mathrm{H}, 4.24 ; \mathrm{N}, 25.42$.

\section{1. 3. 4. 6-(4-Phenylpiperazine-1-yl)-9-(4- trifluoromethylbenzyl)-9H-purine (10)}

Yield $430 \mathrm{mg}$ (97\%), m.p. $122^{\circ} \mathrm{C} .{ }^{1} \mathrm{H}$ NMR $\left(\mathrm{CDCl}_{3}\right)$ $\delta 3.33(\mathrm{t}, 4 \mathrm{H}, J=5.2 \mathrm{~Hz}), 4.82(\mathrm{br} \mathrm{s}, 4 \mathrm{H}), 5.44(\mathrm{~s}, 2 \mathrm{H}), 6.90$ $(\mathrm{t}, 1 \mathrm{H}, J=7.6 \mathrm{~Hz}), 6.98(\mathrm{~d}, 2 \mathrm{H}, J=7.6 \mathrm{~Hz}), 7.29(\mathrm{t}, 2 \mathrm{H}, J=$ $7.6 \mathrm{~Hz}), 7.37(\mathrm{~d}, 2 \mathrm{H}, J=8 \mathrm{~Hz}), 7.59(\mathrm{~d}, 2 \mathrm{H}, J=7.6 \mathrm{~Hz}), 7.76$ $(\mathrm{s}, 1 \mathrm{H}), 8.40(\mathrm{~s}, 1 \mathrm{H}) .{ }^{13} \mathrm{C} \mathrm{NMR}\left(\mathrm{CDCl}_{3}\right) \delta 45.02\left(\mathrm{CH}_{2}\right.$ in piperazine), $46.47\left(\mathrm{CH}_{2}\right), 49.58\left(\mathrm{CH}_{2}\right.$ in piperazine $)$, $116.51,119.85,120.30,122.47,125.17$ (C in phenyl), $125.99\left(\mathrm{q}, J_{C F}=3.8 \mathrm{~Hz}\right), 127.76,129.22,130.58\left(\mathrm{q}, J_{C F}=\right.$ 
$32.8 \mathrm{~Hz}$ ), 138.06 (C in phenyl), 139.79 (C-5), 151.06 (C-8), 151.20 (C-6), 152.83 (C-2), 153.90 (C-4). MS (ESI+) $m / z$ : $439.64(100 \%)(\mathrm{M}+\mathrm{H})$. Anal. Calcd for $\mathrm{C}_{23} \mathrm{H}_{21} \mathrm{~F}_{3} \mathrm{~N}_{6}$. $0.15 \mathrm{H}_{2} \mathrm{O}: \mathrm{C}, 62.61$. Found: $\mathrm{C}, 62.85 ; \mathrm{H}, 4.68 ; \mathrm{N}, 18.66$.

\section{1. 3. 5. 6-[4-(4-Methylphenyl)piperazine-1-yl]-9-(4- trifluoromethylbenzyl)-9H-purine (11)}

Yield $390 \mathrm{mg}$ (86\%), m.p. $156{ }^{\circ} \mathrm{C} .{ }^{1} \mathrm{H}$ NMR $\left(\mathrm{CDCl}_{3}\right)$ $\delta 2.29(\mathrm{~s}, 3 \mathrm{H}), 3.27(\mathrm{t}, 4 \mathrm{H}, J=5.2 \mathrm{~Hz}), 4.48(\mathrm{br} \mathrm{s}, 4 \mathrm{H}), 5.44$ $(\mathrm{s}, 2 \mathrm{H}), 6.90(\mathrm{~d}, 2 \mathrm{H}, J=8.4 \mathrm{~Hz}), 7.10(\mathrm{~d}, 2 \mathrm{H}, J=8 \mathrm{~Hz}), 7.37$ $(\mathrm{d}, 2 \mathrm{H}, J=8 \mathrm{~Hz}), 7.60(\mathrm{~d}, 2 \mathrm{H}, J=8 \mathrm{~Hz}), 7.76(\mathrm{~s}, 1 \mathrm{H}), 8.40$ (s, $1 \mathrm{H}),{ }^{13} \mathrm{C}$ NMR $\left(\mathrm{CDCl}_{3}\right) \delta 20.43\left(\mathrm{CH}_{3}\right), 45.12\left(\mathrm{CH}_{2}\right.$ in piperazine), $46.46\left(\mathrm{CH}_{2}\right), 50.18\left(\mathrm{CH}_{2}\right.$ in piperazine), $116.89,119.84,122.47,125.18$ (C in phenyl), 125.98 (q, $J_{C F}$ $=3.9 \mathrm{~Hz}), 127.75,129.74,129.91,130.58\left(\mathrm{q}, J_{C F}=32.2 \mathrm{~Hz}\right)$, 138.02 (C in phenyl), 139.80 (C-5), 149.11 (C-8), 151.05 (C-6), 152.82 (C-2), 153.90 (C-4). MS (ESI+) m/z: 453.9 $(100 \%)(\mathrm{M}+\mathrm{H})$. Anal. Calcd for $\mathrm{C}_{24} \mathrm{H}_{23} \mathrm{~F}_{3} \mathrm{~N}_{6}$ : C, 63.71; $\mathrm{H}$, 5.12; N, 18.57. Found: C, 63.76; H, 5.10; N, 18.43.

\section{1.3. 6. 6-[4-(4-Trifluoromethylphenyl)piperazine-1- yl]-9-(4-trifluoromethylbenzyl)-9H-purine (12)}

Yield $60 \mathrm{mg}$ (18\%), m.p. $115-118{ }^{\circ} \mathrm{C} .{ }^{1} \mathrm{H}$ NMR $\left(\mathrm{CDCl}_{3}\right) \delta 3.43(\mathrm{t}, 4 \mathrm{H}, J=5.2 \mathrm{~Hz}), 4.48(\mathrm{br} \mathrm{s}, 4 \mathrm{H}), 5.45(\mathrm{~s}$, $2 \mathrm{H}), 6.98(\mathrm{~d}, 2 \mathrm{H}, J=8.4 \mathrm{~Hz}), 7.38(\mathrm{~d}, 2 \mathrm{H}, J=8.4 \mathrm{~Hz}), 7.52$ $(\mathrm{d}, 2 \mathrm{H}, J=8.4 \mathrm{~Hz}), 7.60(\mathrm{~d}, 2 \mathrm{H}, J=8 \mathrm{~Hz}), 7.77(\mathrm{~s}, 1 \mathrm{H}), 8.40$ (s, $1 \mathrm{H}) .{ }^{13} \mathrm{C} \mathrm{NMR}\left(\mathrm{CDCl}_{3}\right) \delta 44.72\left(\mathrm{CH}_{2}\right.$ in piperazine), $46.51\left(\mathrm{CH}_{2}\right), 48.24\left(\mathrm{CH}_{2}\right.$ in piperazine $), 114.85,119.88$, $120.92,121.24,123.28$ (C in phenyl), $126.01\left(\mathrm{q}, J_{C F}=3.8\right.$ $\mathrm{Hz}), 126.48\left(\mathrm{q}, J_{C F}=3.9 \mathrm{~Hz}\right), 127.78,130.47,138.22(\mathrm{C}$ in phenyl), 139.71 (C-5), 151.10 (C-8), 152.81 (C-6), 153.15 (C-2), 153.83 (C-4). MS (ESI+) $\mathrm{m} / z: 507.51 \quad(100 \%)$ $(\mathrm{M}+\mathrm{H})$. Anal. Calcd for $\mathrm{C}_{24} \mathrm{H}_{20} \mathrm{~F}_{6} \mathrm{~N}_{6} \cdot 0.1 \mathrm{H}_{2} \mathrm{O} \cdot 0.3 \mathrm{CH}_{3}$ $\mathrm{COOC}_{2} \mathrm{H}_{5}$ : C, 56.61; H, 4.26; N, 15.71. Found: C, 56.23; H, $3.93 ; \mathrm{N}, 15.43$.

\section{1. 3. 7. 6-[4-(4-Fluorophenyl)piperazine-1-yl]-9-(4- trifluoromethylbenzyl)-9H-purine (13)}

Yield $240 \mathrm{mg}$ (55\%), m.p. $111-113{ }^{\circ} \mathrm{C} .{ }^{1} \mathrm{H}$ NMR $\left(\mathrm{CDCl}_{3}\right) \delta 3.24(\mathrm{t}, 4 \mathrm{H}, J=5.2 \mathrm{~Hz}), 4.48(\mathrm{br} \mathrm{s}, 4 \mathrm{H}), 5.45(\mathrm{~s}$, $2 \mathrm{H}), 6.91-7.02(\mathrm{~m}, 4 \mathrm{H}), 7.37(\mathrm{~d}, 2 \mathrm{H}, J=8.4 \mathrm{~Hz}), 7.60(\mathrm{~d}$, $2 \mathrm{H}, J=8 \mathrm{~Hz}), 7.77(\mathrm{~s}, 1 \mathrm{H}), 8.40(\mathrm{~s}, 1 \mathrm{H}) .{ }^{13} \mathrm{C} \mathrm{NMR}\left(\mathrm{CDCl}_{3}\right)$ $\delta 45.04\left(\mathrm{CH}_{2}\right.$ in piperazine $), 46.48\left(\mathrm{CH}_{2}\right), 50.62\left(\mathrm{CH}_{2}\right.$ in piperazine), $115.65(\mathrm{~d}, J=21.9 \mathrm{~Hz}), 118.39(\mathrm{~d}, J=7.7 \mathrm{~Hz})$, $119.85,122.46,125.16$ (C in phenyl), $125.99\left(\mathrm{q}, J_{C F}=3.9\right.$ $\mathrm{Hz}), 127.76,130.60\left(\mathrm{q}, J_{C F}=32.8 \mathrm{~Hz}\right), 138.08$ (C in phenyl), 139.77 (C-5), 147.89 (C-8), 151.07 (C-6), 152.81 (C-2), 153.88 (C-4), $157.50(\mathrm{~d}, \mathrm{~J}=239.3)$. MS (ESI+) $m / z: \quad 457.57 \quad(100 \%) \quad(\mathrm{M}+\mathrm{H})$. Anal. Calcd for $\mathrm{C}_{23} \mathrm{H}_{20} \mathrm{~F}_{4} \mathrm{~N}_{6} \cdot 0.2 \mathrm{H}_{2} \mathrm{O}: \mathrm{C}, 60.05 ; \mathrm{H}, 4.47 ; \mathrm{N}, 18.27$. Found: $\mathrm{C}$, $59.83 ; \mathrm{H}, 4.30 ; \mathrm{N}, 18.11$.

\section{1. 3. 8. 6-[4-(2,4-Difluorophenyl)piperazine-1-yl]-9- (4-trifluoromethylbenzyl)-9H-purine (14) \\ Yield $420 \mathrm{mg}$ (89\%), m.p. $193^{\circ} \mathrm{C} .{ }^{1} \mathrm{H}$ NMR $\left(\mathrm{CDCl}_{3}\right)$ $\delta 3.16(\mathrm{t}, 4 \mathrm{H}, J=5.2 \mathrm{~Hz}), 4.49(\mathrm{br} \mathrm{s}, 4 \mathrm{H}), 5.45(\mathrm{~s}, 2 \mathrm{H})$,}

6.78-6.98 (m, 3H), $7.37(\mathrm{~d}, 2 \mathrm{H}, J=8 \mathrm{~Hz}), 7.60(\mathrm{~d}, 2 \mathrm{H}, J=$ $8 \mathrm{~Hz}), 7.76(\mathrm{~s}, 1 \mathrm{H}), 8.40(\mathrm{~s}, 1 \mathrm{H}) .{ }^{13} \mathrm{C} \mathrm{NMR}\left(\mathrm{CDCl}_{3}\right) \delta 45.21$ $\left(\mathrm{CH}_{2}\right.$ in piperazine $), 46.48\left(\mathrm{CH}_{2}\right), 51.19\left(\mathrm{CH}_{2}\right.$ in piperazine), 104.84 (t, $J=24.5 \mathrm{~Hz}), 110.78$ (dd, $J=3.8, J=21.9)$, $119.81(\mathrm{dd}, J=3.9 \mathrm{~Hz}, J=10.3 \mathrm{~Hz}), 122.46,125.16(\mathrm{C}$ in phenyl), $125.99\left(\mathrm{q}, J_{C F}=3.2 \mathrm{~Hz}\right), 127.77,130.59\left(\mathrm{q}, J_{C F}=\right.$ $32.2 \mathrm{~Hz}), 136.49(\mathrm{dd}, J=3.8, J=9 \mathrm{~Hz})$, (C in phenyl), 138.05 (C-5), 139.78 (C-8), 151.08 (C-6), 152.81 (C-2), $153.91(\mathrm{C}-4), 155.75$ (dd, $J=11.6 \mathrm{~Hz}, J=237.3), 158.22(\mathrm{dd}$, $J=7.7 \mathrm{~Hz}, J=232.2 \mathrm{~Hz}$ ), (C in phenyl). MS (ESI+) $m / z$ : $475.82(100 \%)(\mathrm{M}+\mathrm{H})$. Anal. Calcd for $\mathrm{C}_{23} \mathrm{H}_{19} \mathrm{~F}_{5} \mathrm{~N}_{6}$ : C, 58.23; H, 4.04; N, 17.71. Found: C, 58.29; H, 4.17; N, 17.52.

\section{1. 3. 9. 6-[4-(3,4-Dichlorophenyl)piperazine-1-yl]-9- (4-trifluoromethylbenzyl)-9H-purine (15)}

Yield $450 \mathrm{mg}$ (88\%), m.p. $136{ }^{\circ} \mathrm{C} .{ }^{1} \mathrm{H}$ NMR $\left(\mathrm{CDCl}_{3}\right)$ $\delta 3.30(\mathrm{t}, 4 \mathrm{H}, J=4.8 \mathrm{~Hz}), 4.47(\mathrm{br} \mathrm{s}, 4 \mathrm{H}), 5.45(\mathrm{~s}, 2 \mathrm{H}), 6.79$ $(\mathrm{dd}, 1 \mathrm{H}, J=9.2 \mathrm{~Hz}, J=3.2 \mathrm{~Hz}), 7.00(\mathrm{~d}, 3 \mathrm{H}, J=2.8 \mathrm{~Hz})$, $7.30(\mathrm{~d}, 1 \mathrm{H}, J=9.2 \mathrm{~Hz}), 7.37(\mathrm{~d}, 2 \mathrm{H}, J=8.4 \mathrm{~Hz}), 7.60(\mathrm{~d}$, $2 \mathrm{H}, J=8 \mathrm{~Hz}) 7.77(\mathrm{~s}, 1 \mathrm{H}), 8.40(\mathrm{~s}, 1 \mathrm{H}) .{ }^{13} \mathrm{C} \mathrm{NMR}\left(\mathrm{CDCl}_{3}\right)$ $\delta 44.71\left(\mathrm{CH}_{2}\right.$ in piperazine $), 46.50\left(\mathrm{CH}_{2}\right), 49.02\left(\mathrm{CH}_{2}\right.$ in piperazine), $115.69,117.65,119.88,122.45,122.80,125.16$, (C in phenyl), $126.01\left(\mathrm{q}, J_{C F}=3.8 \mathrm{~Hz}\right), 127.78,130.54$, $130.62\left(\mathrm{q}, J_{C F}=32.9 \mathrm{~Hz}\right), 132.90,138.21(\mathrm{C}$ in phenyl), 139.71 (C-5), 150.55 (C-8), 151.11 (C-6), 152.80 (C-2), $153.81(\mathrm{C}-4)$. MS (ESI+) $\mathrm{m} / z: 507.7(100 \%)\left(\mathrm{M}^{+}\right), 509.7$ (63\%) (M+2), $511.9 \quad(5 \%)(\mathrm{M}+4)$. Anal. Calcd for $\mathrm{C}_{23} \mathrm{H}_{19} \mathrm{Cl}_{2} \mathrm{~N}_{6}$ : C, 54.45; H, 3.77; N, 16.56. Found: C, 54.43; $\mathrm{H}, 3.70 ; \mathrm{N}, 16.54$.

\section{1. 3. 10. 6-[4-(Diphenylmethyl)piperazine-1-yl]-9-(4- trifluoromethylbenzyl)-9H-purine (16)}

Yield $340 \mathrm{mg}$ (65\%), m.p. $179-182{ }^{\circ} \mathrm{C} .{ }^{1} \mathrm{H}$ NMR $\left(\mathrm{CDCl}_{3}\right) \delta 2.53(\mathrm{t}, 4 \mathrm{H}, J=5.2 \mathrm{~Hz}), 4.28(\mathrm{~s}, 1 \mathrm{H}), 4.31(\mathrm{br} \mathrm{s}$, $4 \mathrm{H}), 5.40(\mathrm{~s}, 2 \mathrm{H}), 7.17-7.36(\mathrm{~m}, 8 \mathrm{H}), 7.44(\mathrm{~d}, 4 \mathrm{H}, J=7.2$ $\mathrm{Hz}), 7.58(\mathrm{~d}, 2 \mathrm{H}, J=8.4 \mathrm{~Hz}), 7.67(\mathrm{~s}, 1 \mathrm{H}), 8.33(\mathrm{~s}, 1 \mathrm{H}) .{ }^{13} \mathrm{C}$ NMR $\left(\mathrm{CDCl}_{3}\right) \delta 42.82\left(\mathrm{CH}_{2}\right.$ in piperazine $), 43.82\left(\mathrm{CH}_{2}\right)$, $49.45\left(\mathrm{CH}_{2}\right.$ in piperazine), $73.53(\mathrm{CH}), 117.19,119.91$, 122.61 (C in phenyl), $123.3\left(\mathrm{q}, J_{C F}=3.9 \mathrm{~Hz}\right), 124.51$, $125.17,125.41,125.96,128.95\left(\mathrm{q}, J_{C F}=32.9 \mathrm{~Hz}\right), 135.17(\mathrm{C}$ in phenyl), 137.28 (C-5), 139.64 (C-8), 148.35 (C-6), 150.24 (C-2), 151.32 (C-4). MS (ESI+) $m / z: 529.68$ (100\%) $(\mathrm{M}+\mathrm{H})$. Anal. Calcd for $\mathrm{C}_{30} \mathrm{H}_{27} \mathrm{~F}_{3} \mathrm{~N}_{6}: \mathrm{C}, 68.17 ; \mathrm{H}, 5.15 ; \mathrm{N}$, 15.90. Found: C, 67.90; H, 5.09; N, 15.71 .

\section{1. 3. 11. 6-[4-(2-Hydroxyethyl)piperazine-1-yl]-9-(4- chlorobenzyl)-9H-purine (17)}

Yield $290 \mathrm{mg}$ (77\%), m.p. $138-141{ }^{\circ} \mathrm{C} .{ }^{1} \mathrm{H}$ NMR $\left(\mathrm{CDCl}_{3}\right) \delta 2.61(\mathrm{t}, 2 \mathrm{H}, J=5.6 \mathrm{~Hz}), 2.66(\mathrm{t}, 4 \mathrm{H}, J=5.6 \mathrm{~Hz})$, $3.68(\mathrm{t}, 2 \mathrm{H}, J=5.2 \mathrm{~Hz}), 3.77(\mathrm{br} \mathrm{s}, 4 \mathrm{H}), 5.34(\mathrm{~s}, 2 \mathrm{H}), 7.21(\mathrm{~d}$, $2 \mathrm{H}, J=8.4 \mathrm{~Hz}), 7.31(\mathrm{~d}, 2 \mathrm{H}, J=8.4 \mathrm{~Hz}), 7.71(\mathrm{~s}, 1 \mathrm{H}), 8.37$ (s, $1 \mathrm{H}) .{ }^{13} \mathrm{C}$ NMR $\left(\mathrm{CDCl}_{3}\right) \delta 45.11\left(\mathrm{CH}_{2}\right.$ in piperazine), $46.34\left(\mathrm{CH}_{2}\right), 53.01\left(\mathrm{CH}_{2}\right.$ in piperazine $), 57.76\left(\mathrm{CH}_{2}-\mathrm{N}\right)$, $59.46\left(\mathrm{CH}_{2}-\mathrm{OH}\right), 119.79,128.98,129.16,134.26(\mathrm{C}$ in phenyl), 134.31 (C-5), 137.99 (C-8), 150.98 (C-6), 152.68 (C-2), 153.84 (C-4). MS (ESI+) $m / z: 373.61(100 \%)$ 
$(\mathrm{M}+\mathrm{H}), \quad 375.62 \quad(33 \%) \quad(\mathrm{M}+\mathrm{H}+2)$. Anal. Calcd for $\mathrm{C}_{18} \mathrm{H}_{21} \mathrm{ClN}_{6} \mathrm{O} \cdot 0.4 \mathrm{H}_{2} \mathrm{O}: \mathrm{C}, 56.88 ; \mathrm{H}, 5.78 ; \mathrm{N}, 22.11$. Found: C, 56.65; H, 5.44; N, 21.88 .

\section{1. 3. 12. 6-[4-Cyclohexylpiperazine-1-yl]-9-(4- chlorobenzyl)-9H-purine (18)}

Yield $380 \mathrm{mg}$ (93\%), m.p. $125^{\circ} \mathrm{C} .{ }^{1} \mathrm{H} \mathrm{NMR}\left(\mathrm{CDCl}_{3}\right) \delta$ 1.09-1.99 (m, 10H), 2.54 (br s, 1H), 2.86 (br s, $4 \mathrm{H}), 4.47$ (br s, $4 \mathrm{H}), 5.31(\mathrm{~s}, 2 \mathrm{H}), 7.19(\mathrm{~d}, 2 \mathrm{H}, J=8.4 \mathrm{~Hz}), 7.29(\mathrm{~d}, 2 \mathrm{H}$, $J=8.4 \mathrm{~Hz}), 7.70(\mathrm{~s}, 1 \mathrm{H}), 8.35(\mathrm{~s}, 1 \mathrm{H}) .{ }^{13} \mathrm{C} \mathrm{NMR}\left(\mathrm{CDCl}_{3}\right) \delta$ 25.57, 25.82, $28.11\left(\mathrm{CH}_{2}\right.$ in cyclohexyl), $44.31\left(\mathrm{CH}_{2}\right.$ in piperazine), $45.78\left(\mathrm{CH}_{2}\right), 48.86\left(\mathrm{CH}_{2}\right.$ in piperazine $), 64.53$ (CH in cyclohexyl), 119.80, 129.01, 129.16 (C in phenyl), 134.26 (C-5), 138.20 (C-8), 151.02 (C-6), 152.66 (C-2), $153.55(\mathrm{C}-4)$. MS (ESI+) $m / z: 411.75(100 \%)(\mathrm{M}+\mathrm{H})$, $413.74(30 \%)(\mathrm{M}+\mathrm{H}+2)$. Anal. Calcd for $\mathrm{C}_{22} \mathrm{H}_{27} \mathrm{ClN}_{6}$ : C, 64.30; H, 6.62; N, 20.45. Found: C, 64.28; H, 6.84; N, 20.12.

\section{1. 3. 13. 6-[4-(Pyrimidine-2-yl)piperazine-1-yl]-9-(4- chlorobenzyl)-9H-purine (19)}

Yield $280 \mathrm{mg}$ (69\%), m.p. $202{ }^{\circ} \mathrm{C} .{ }^{1} \mathrm{H} \mathrm{NMR}\left(\mathrm{CDCl}_{3}\right) \delta$ $3.99(\mathrm{t}, 4 \mathrm{H}, J=5.6 \mathrm{~Hz}), 4.40(\mathrm{br} \mathrm{s}, 4 \mathrm{H}), 5.35$ (s, 2H), $6.54(\mathrm{t}$, $1 \mathrm{H}, J=4.4 \mathrm{~Hz}), 7.21(\mathrm{~d}, 2 \mathrm{H}, J=8.8 \mathrm{~Hz}), 7.32(\mathrm{~d}, 2 \mathrm{H}, J=8$ $\mathrm{Hz}), 7.74(\mathrm{~s}, 1 \mathrm{H}), 8.34(\mathrm{~d}, 2 \mathrm{H}, J=4.4 \mathrm{~Hz}), 8.41(\mathrm{~s}, 1 \mathrm{H}) .{ }^{13} \mathrm{C}$ NMR $\left(\mathrm{CDCl}_{3}\right) \delta 43.76\left(\mathrm{CH}_{2}\right.$ in piperazine $), 44.98\left(\mathrm{CH}_{2}\right.$ in piperazine), $46.36\left(\mathrm{CH}_{2}\right), 110.22$ (C-5 in pyrimidine), $119.91,128.99,129.17,134.26$ (C in phenyl), 134.30 (C-5), 138.12 (C-8), 151.02 (C-6), 152.69 (C-2), 154.01 (C-4), 157.76 (C-4,6 in pyrimidine), 161.67 (C-2 in pyrimidine). MS (ESI+) $m / z: 407.77$ (100\%) $(\mathrm{M}+\mathrm{H}), 409.84(32 \%)$ $(\mathrm{M}+\mathrm{H}+2)$. Anal. Calcd for $\mathrm{C}_{20} \mathrm{H}_{19} \mathrm{ClN}_{8} \cdot 0.43 \mathrm{MeOH}: \mathrm{C}$, 58.34; H, 4.96; N, 27.54. Found: C, 58.73; H, 5.18; N, 26.27.

\section{1. 3. 14. 6-(4-Phenylpiperazine-1-yl)-9-(4- chlorobenzyl)-9H-purine (20)}

Yield $120 \mathrm{mg}$ (82\%), m.p. $140-143{ }^{\circ} \mathrm{C} .{ }^{1} \mathrm{H}$ NMR $\left(\mathrm{CDCl}_{3}\right) \delta 3.33(\mathrm{t}, 4 \mathrm{H}, J=5.2 \mathrm{~Hz}), 4.48(\mathrm{br} \mathrm{s}, 4 \mathrm{H}), 5.35(\mathrm{~s}$, $2 \mathrm{H}), 6.91(\mathrm{t}, 1 \mathrm{H}, J=7.6 \mathrm{~Hz}), 6.98(\mathrm{~d}, 2 \mathrm{H}, J=8 \mathrm{~Hz}), 7.21(\mathrm{~d}$, $2 \mathrm{H}, J=8.8 \mathrm{~Hz}), 7.25-7.34(\mathrm{~m}, 4 \mathrm{H}), 7.73(\mathrm{~s}, 1 \mathrm{H}), 8.40(\mathrm{~s}$, $1 \mathrm{H}) .{ }^{13} \mathrm{C} \mathrm{NMR}\left(\mathrm{CDCl}_{3}\right) \delta 45.04\left(\mathrm{CH}_{2}\right.$ in piperazine $), 46.36$ $\left(\mathrm{CH}_{2}\right), 49.58\left(\mathrm{CH}_{2}\right.$ in piperazine $), 116.50,119.87,120.28$, $128.99,129.18,129.21,134.28,134.30$ (C in phenyl), 138.10 (C-5), 151.04 (C-8), 151.21 (C-6), 152.73 (C-2), $153.88(\mathrm{C}-4)$. MS (ESI+) $m / z: 405.69$ (100\%) $(\mathrm{M}+\mathrm{H})$, $407.69(\% 47)(\mathrm{M}+\mathrm{H}+2)$. Anal. Calcd for $\mathrm{C}_{22} \mathrm{H}_{21} \mathrm{ClN}_{6}$ : C, 65.26; H, 5.23; N, 20.76. Found: C, 65.24; H, 5.04; N, 20.70.

\section{1. 3. 15. 6-[4-(4-Methylphenyl)piperazine-1-yl]-9-(4- chlorobenzyl)-9H-purine (21)}

Yield $310 \mathrm{mg}(75 \%)$, m.p. $193{ }^{\circ} \mathrm{C} .{ }^{1} \mathrm{H}$ NMR $\left(\mathrm{CDCl}_{3}\right)$ $\delta 2.28(\mathrm{~s}, 3 \mathrm{H}), 3.26$ (t, $4 \mathrm{H}, J=4.8 \mathrm{~Hz}$ ), 4.47 (br s, $4 \mathrm{H}), 5.34$ $(\mathrm{s}, 2 \mathrm{H}), 6.90(\mathrm{~d}, 2 \mathrm{H}, J=8.4 \mathrm{~Hz}), 7.10(\mathrm{~d}, 2 \mathrm{H}, J=8 \mathrm{~Hz}), 7.21$ $(\mathrm{d}, 2 \mathrm{H}, J=8.8 \mathrm{~Hz}), 7.31(\mathrm{~d}, 2 \mathrm{H}, J=8 \mathrm{~Hz}), 7.73(\mathrm{~s}, 1 \mathrm{H}), 8.40$ (s, 1H). ${ }^{13} \mathrm{C} \mathrm{NMR}\left(\mathrm{CDCl}_{3}\right) \delta 20.44\left(\mathrm{CH}_{3}\right), 45.03\left(\mathrm{CH}_{2}\right.$ in piperazine), $46.37\left(\mathrm{CH}_{2}\right), 50.23\left(\mathrm{CH}_{2}\right.$ in piperazine $)$, $116.92,119.85,128.99,129.18,129.74,129.97,134.29$ (C in phenyl), 138.08 (C-5), 149.06 (C-8), 151.01 (C-6), 152.69 (C-2), 153.84 (C-4). MS (ESI+) $m / z: 419.78$ (100\%) $(\mathrm{M}+\mathrm{H}), 421.81(45 \%)(\mathrm{M}+\mathrm{H}+2)$. Anal. Calcd for $\mathrm{C}_{23} \mathrm{H}-$ ${ }_{23} \mathrm{ClN}_{6} \cdot 0.2 \mathrm{H}_{2} \mathrm{O}$ : C, 65.38; H, 5.58; N, 19.89. Found: C, $65.94 ; \mathrm{H}, 5.53 ; \mathrm{N}, 20.06$.

\section{1. 3. 16. 6-[4-(4-Trifluoromethylphenyl)piperazine- 1-yl]-9-(4-chlorobenzyl)-9H-purine (22)}

Yield $330 \mathrm{mg}(69 \%)$, m.p. $162{ }^{\circ} \mathrm{C} .{ }^{1} \mathrm{H}$ NMR $\left(\mathrm{CDCl}_{3}\right)$ $\delta 3.43(\mathrm{t}, 4 \mathrm{H}, J=4.8 \mathrm{~Hz}), 4.48(\mathrm{br} \mathrm{s}, 4 \mathrm{H}), 5.35$ (s, 2H), 6.98 $(\mathrm{d}, 2 \mathrm{H}, J=8.4 \mathrm{~Hz}), 7.22(\mathrm{~d}, 2 \mathrm{H}, J=8.8 \mathrm{~Hz}), 7.31(\mathrm{~d}, 2 \mathrm{H}, J=$ $8.4 \mathrm{~Hz}), 7.51(\mathrm{~d}, 2 \mathrm{H}, J=8.4 \mathrm{~Hz}), 7.40(\mathrm{~s}, 1 \mathrm{H}), 8.40(\mathrm{~s}, 1 \mathrm{H})$. ${ }^{13} \mathrm{C} \mathrm{NMR}\left(\mathrm{CDCl}_{3}\right) \delta 44.78\left(\mathrm{CH}_{2}\right.$ in piperazine), 46.43 $\left(\mathrm{CH}_{2}\right), 48.22\left(\mathrm{CH}_{2}\right.$ in piperazine $), 114.84,119.87,120.89$, 121.21, 125.97 (C in phenyl), $126.48\left(\mathrm{q}, J_{C F}=3.8 \mathrm{~Hz}\right)$, $129,02,129.21,134.20$ (C in phenyl), 138.31 (C-5), 151.01 (C-8), 152.55 (C-6), 153.13 (C-2), 153.67 (C-4). MS (ESI+) $m / z: 473.54(100 \%)(\mathrm{M}+\mathrm{H}), 475.52(40 \%)(\mathrm{M}+\mathrm{H}+2)$. Anal. Calcd for $\mathrm{C}_{23} \mathrm{H}_{20} \mathrm{ClF}_{3} \mathrm{~N}_{6}$ : C, 58.42; H, 4.26; N, 17.77 . Found: C, 58.55; H, 4.30; N, 17.60.

\section{1. 3. 17. 6-[4-(4-Fluorophenyl)piperazine-1-yl]-9-(4- chlorobenzyl)-9H-purine (23)}

Yield $280 \mathrm{mg}(67 \%)$, m.p. $186-188{ }^{\circ} \mathrm{C} .{ }^{1} \mathrm{H}$ NMR $\left(\mathrm{CDCl}_{3}\right) \delta 3.23(\mathrm{t}, 4 \mathrm{H}, J=5.2 \mathrm{~Hz}), 4.47$ (br s, $\left.4 \mathrm{H}\right), 5.35$ (s, $2 \mathrm{H}), 6.91-7.02(\mathrm{~m}, 4 \mathrm{H}), 7.21(\mathrm{~d}, 2 \mathrm{H}, J=8.4 \mathrm{~Hz}), 7.31(\mathrm{~d}, 2 \mathrm{H}$, $J=8 \mathrm{~Hz}), 7.73(\mathrm{~s}, 1 \mathrm{H}), 8.40(\mathrm{~s}, 1 \mathrm{H}) .{ }^{13} \mathrm{C} \mathrm{NMR}\left(\mathrm{CDCl}_{3}\right) \delta$ $40.31\left(\mathrm{CH}_{2}\right.$ in piperazine $), 41.62\left(\mathrm{CH}_{2}\right), 45.87\left(\mathrm{CH}_{2}\right.$ in piperazine), $110.89(\mathrm{~d}, J=21.9 \mathrm{~Hz}), 113.64(\mathrm{~d}, J=7.7 \mathrm{~Hz})$, $115.12,124.24,124.43,129.52,129.54$ (C in phenyl), 133.38 (C-5), 143.13 (C-8), 146.28 (C-6), 147.93 (C-2), 149.08 (C-4), $152.75(\mathrm{~d}, J=239.9)$. MS (ESI+) $m / z: 424(100 \%)(\mathrm{M}+\mathrm{H})$, $425.94(35 \%)(\mathrm{M}+\mathrm{H}+2)$. Anal. Calcd for $\mathrm{C}_{22} \mathrm{H}_{20} \mathrm{ClFN}_{6}$ : C, 62.48; H, 4.77; N, 19.87. Found: C, 62.55; H, 4.57; N, 19.84.

\section{1. 3. 18. 6-[4-(2,4-Difluorophenyl)piperazine-1-yl]-9- (4-chlorobenzyl)-9H-purine (24)}

Yield $410 \mathrm{mg}$ (93\%), m.p. $183-185{ }^{\circ} \mathrm{C} .{ }^{1} \mathrm{H}$ NMR $\left(\mathrm{CDCl}_{3}\right) \delta 3.15(\mathrm{t}, 4 \mathrm{H}, J=4.8 \mathrm{~Hz}), 4.48(\mathrm{br} \mathrm{s}, 4 \mathrm{H}), 5.35(\mathrm{~s}$, $2 \mathrm{H}), 6.78-6.96(\mathrm{~m}, 3 \mathrm{H}), 7.22(\mathrm{~d}, 2 \mathrm{H}, J=8.4 \mathrm{~Hz}), 7.32(\mathrm{~d}$, $2 \mathrm{H}, J=8 \mathrm{~Hz}), 7.73(\mathrm{~s}, 1 \mathrm{H}), 8.40(\mathrm{~s}, 1 \mathrm{H}) .{ }^{13} \mathrm{C} \mathrm{NMR}\left(\mathrm{CDCl}_{3}\right)$ $\delta 40.53\left(\mathrm{CH}_{2}\right.$ in piperazine $), 41.63\left(\mathrm{CH}_{2}\right), 46.44\left(\mathrm{CH}_{2}\right.$ in piperazine), $100.08(\mathrm{t}, J=24.4 \mathrm{~Hz}), 106.03(\mathrm{dd}, J=21.3 \mathrm{~Hz}$, $J=3.9 \mathrm{~Hz}), 115.05(\mathrm{dd}, J=9.1 \mathrm{~Hz}, J=3.8 \mathrm{~Hz}), 124.25$, $124.43,129.52,131.71(\mathrm{dd}, J=9.1 \mathrm{~Hz}, \mathrm{~J}=3.9$ ), (C in phenyl), 133.35 (C-5), 145.51 (C-8), 146.28 (C-6), 147.90 (C-2), 149.09 (C-4), 151.03 (dd, $J=240.6, J=11.6 \mathrm{~Hz}$ ), 153.46 (dd, $J=231.6, J=12.2$ ) (C in phenyl). MS (ESI+) $m / z: 441.8(100 \%)(\mathrm{M}+\mathrm{H}), 443.8(37 \%)(\mathrm{M}+\mathrm{H}+2)$. Anal. Calcd for $\mathrm{C}_{22} \mathrm{H}_{19} \mathrm{ClF}_{2} \mathrm{~N}_{6}$ : C, 59.93; H, 4.34; N, 19.06 . Found: C, 59.87; H, 4.24; N, 19.11.

\section{1. 3. 19. 6-[4-(3,4-Dichlorophenyl)piperazine-1-yl]- 9-(4-chlorobenzyl)-9H-purine (25)}

Yield $440 \mathrm{mg}$ (92\%), m.p. $198-200{ }^{\circ} \mathrm{C} .{ }^{1} \mathrm{H}$ NMR $\left(\mathrm{CDCl}_{3}\right) \delta 3.30(\mathrm{t}, 4 \mathrm{H}, J=4.8 \mathrm{~Hz}), 4.46($ br s, $4 \mathrm{H}), 5.35$ (s, 
$2 \mathrm{H}), 6.79(\mathrm{dd}, 1 \mathrm{H}, J=2.8 \mathrm{~Hz}, J=9.2 \mathrm{~Hz}), 7.00(\mathrm{~d}, 1 \mathrm{H}, J=$ $2.8 \mathrm{~Hz}), 7.22(\mathrm{~d}, 2 \mathrm{H}, J=8.8 \mathrm{~Hz}), 7.29-7.33(\mathrm{~m}, 3 \mathrm{H}), 7.74(\mathrm{~s}$, $1 \mathrm{H}), 8.40(\mathrm{~s}, 1 \mathrm{H}) .{ }^{13} \mathrm{C} \mathrm{NMR}\left(\mathrm{CDCl}_{3}\right) \delta 44.75\left(\mathrm{CH}_{2}\right.$ in piperazine), $46.41\left(\mathrm{CH}_{2}\right), 49.01\left(\mathrm{CH}_{2}\right.$ in piperazine $), 115.69$, $117.64,119.89,122.79,129.01,129.20,130.54,132.90$, 134.22, 134.32 (C in phenyl), 138.26 (C-5), 150.56 (C-8), 151.05 (C-6), 152.65 (C-2), 153.75 (C-4). MS (ESI+) $m / z$ : $473.7(100 \%)\left(\mathrm{M}^{+}\right), 475.8(90 \%)(\mathrm{M}+2), 477.8$ (35\%) $(\mathrm{M}+4)$. Anal. Calcd for $\mathrm{C}_{22} \mathrm{H}_{19} \mathrm{Cl}_{3} \mathrm{~N}_{6}$ : C, 55.77; $\mathrm{H}, 4.04 ; \mathrm{N}$, 17.74. Found: C, 55.50; H, 4.08; N, 17.86 .

\section{1. 3. 20. 6-[4-(Diphenylmethyl)piperazine-1-yl]-9-(4- chlorobenzyl)-9H-purine (26)}

Yield $310 \mathrm{mg}$ (62\%), m.p. $145-147{ }^{\circ} \mathrm{C} .{ }^{1} \mathrm{H}$ NMR $\left(\mathrm{CDCl}_{3}\right) \delta 2.53(\mathrm{~m}, 4 \mathrm{H}), 4.28(\mathrm{~s}, 1 \mathrm{H}), 4.30$ (br s, $\left.4 \mathrm{H}\right), 5.28$ (s, 2H), 7.14-7.22 (m, 4H), 7.25-7.31 (m, 6H), $7.44(\mathrm{~d}, 4 \mathrm{H}$, $J=7.2 \mathrm{~Hz}), 7.63(\mathrm{~s}, 1 \mathrm{H}), 8.34(\mathrm{~s}, 1 \mathrm{H}) .{ }^{13} \mathrm{C} \mathrm{NMR}\left(\mathrm{CDCl}_{3}\right) \delta$ $45.37\left(\mathrm{CH}_{2}\right.$ in piperazine $), 46.28\left(\mathrm{CH}_{2}\right), 52.03\left(\mathrm{CH}_{2}\right.$ in piperazine), $76.10(\mathrm{CH}), 119.79,127.06,127.98,128.52$, $128.98,129.14,134.20,134.36$ (C in phenyl), 137.79 (C-5), 142.22 (C-8), 150.89 (C-6), 152.70 (C-2), 153.86 (C-4). MS $(\mathrm{ESI}+) \quad m / z: \quad 495.67 \quad(100 \%) \quad(\mathrm{M}+\mathrm{H}), \quad 497.66 \quad(39 \%)$ $(\mathrm{M}+\mathrm{H}+2)$. Anal. Calcd for $\mathrm{C}_{29} \mathrm{H}_{27} \mathrm{ClN}_{6}$ : C, 70.36; $\mathrm{H}, 5.50$; N, 16.98. Found: C, 70.17; H, 5.20; N, 16.92.

\section{2. Biological Evaluation}

\section{2. 1. Cells and Culture}

The human primary liver cancer cell lines (Huh7, HepG2, Mahlavu and FOCUS) were grown in Dulbecco's Modified Eagle's Medium (DMEM) (Invitrogen GIBCO) with $10 \%$ fetal bovine serum (FBS) (Invitrogen GIBCO), nonessential amino acids, and $1 \%$ penicillin (Biochrome). It was incubated at $37{ }^{\circ} \mathrm{C}$ with $5 \% \mathrm{CO}_{2}$. DMSO (Sigma) was used as the solvent for the compounds. The concentration of DMSO was always less than $1 \%$ in the cell culture medium. The cytotoxic drugs (camptothecin (CPT), 5-fluorouracil (5-FU), fludarabine, and cladribine) used as positive controls were from Calbiochem.

\section{2. 2. Sulforhodamine B (SRB) Assay for Cytotoxicity Screening}

Huh7, HCT116, MCF7, HepG2, Mahlavu, and FOCUS cells were inoculated (2000-10000 cells/well in 200 $\mu \mathrm{L})$ in 96-well plates. The next day, the media was refreshed, and the compounds dissolved in DMSO were applied in concentrations between 1 and $40 \mu \mathrm{M}$ in parallel with DMSO-only treated cells as negative controls. At the 72nd hour of treatment with compounds 7-26 and the other drugs, the cancer cells were fixed with $100 \mu \mathrm{L}$ of $10 \%$ (w/v) trichloroacetic acid (TCA) and kept at $+4{ }^{\circ} \mathrm{C}$ in dark for $1 \mathrm{~h}$. TCA fixation was terminated by washing the wells with $\mathrm{ddH}_{2} \mathrm{O}$ five times. Air-dried plates were stained with $0.4 \%$ sulphorhodamine B (SRB) dissolved in $1 \%$ acetic acid solution for $10 \mathrm{~min}$ in the dark and at room tempera- ture. The protein-bound and dried SRB dye was then solubilized with 10 mMTris-Base $\mathrm{pH} 8$. The absorbance values were obtained at $515 \mathrm{~nm}$ in a microplate reader. The data normalized against DMSO-only treated wells, which were used as controls in serial dilutions. In all experiments, a linear response was observed, with serial dilutions of the compounds and the drugs.

\section{Results and Discussion}

\section{1. Chemistry}

The 6-(4-substituted piperazine-1-yl)-9-(4-substituted benzyl)purine analogs were synthesized in four steps starting with commercially available 4,6-dichloro-5-nitropyrimidine (1) (Scheme 1). The dichloronitropyrimidine was reduced to the corresponding dichloroaminopyrimidine (2) with stannous chloride and ethanol..$^{53}$ Amination of 5-amino-4,6-dichloropyrimidine (2) with the appropriate benzylamines gave the 4-(4-substituted benzyl)pyrimidines $(3,4)$. Condensation of compounds 3,4 with triethyorthoformate and para-toluenesulfonic acid afforded the intermediate 6-chloro-9-(4-substituted benzyl)purines 5, 6. ${ }^{54}$ Purines substituted at C-6 (7-26) were synthesized by nucleophilic substitution of the chlorine of 9 -substituted purines $(5,6)$ with the appropriate 4 -substituted piperazines in the presence of base.

\section{2. Biological Evaluation}

The antitumor activities of newly synthesized purine analogues were first analyzed on three human cancer cell lines including Huh7 (liver), HCT116 (colon) and MCF7 (breast) cancer cells by using the sulforhodamine B (SRB) method. The $\mathrm{IC}_{50}$ values of the purine compounds were calculated in comparison with DNA topoisomerase inhibitor camptothecin (CPT) and the known cell growth inhibitors fludarabine, cladribine, 5 -fluorouracil (5-FU). The data are summarized in Table 1.

All synthesized purine derivatives in this study, except for compound 19, exhibited important cytotoxic activity against cancer cells Huh7, HCT116, MCF7 with IC $_{50}$ from 0.05 to $21.7 \mu \mathrm{M}$.

As seen from the data in Table 1, all the 6-(trifluoromethylphenyl)piperazine purines, 12 and 22 exhibited excellent cytotoxic activities with $\mathrm{IC}_{50} 0.08-0.13 \mu \mathrm{M}$ on Huh7 cells comparable to CPT and better than cladribine, fludarabine and 5-FU. In addition, compounds $\mathbf{1 5}$ and $\mathbf{2 5}$ bearing a 3,4-dichlorophenyl group at the piperazine of the purine, presented a higher cytotoxic activity than known nucleoside drugs cladribine, fludarabine and nucleobase drug 5-FU on Huh7 cells. For the 4-fluorophenyl substituted derivatives $\mathbf{1 3}$ and $\mathbf{2 3}$, their best activity is observed for the 9-(4-chlorobenzyl) purine derivative $\mathbf{2 3}$ with $\mathrm{IC}_{50}$ value of $0.57 \mu \mathrm{M}$ on Huh7. Cytotoxic activity differences were not observed in the nonsubstituted phe- 
<smiles>O=[N+]([O-])c1c(Cl)ncnc1Cl</smiles>

1<smiles>C=CC</smiles><smiles>[CH]C</smiles><smiles>[R7]c1ccc(CN(C)/C=N\CC)cc1</smiles>

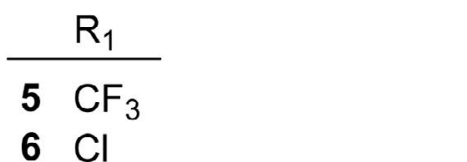<smiles>Nc1c(Cl)ncnc1Cl</smiles>

2

$b$<smiles>[R]c1ccc(CNc2ncnc(Cl)c2N)cc1</smiles>

\begin{tabular}{ll} 
& $\mathrm{R}_{1}$ \\
\hline 3 & $\mathrm{CF}_{3}$ \\
4 & $\mathrm{Cl}$
\end{tabular}<smiles>CC1CC1</smiles><smiles>[R7]c1ccc(Cn2cnc3c(N4CCN([R])CC4)ncnc32)cc1</smiles>

7-26
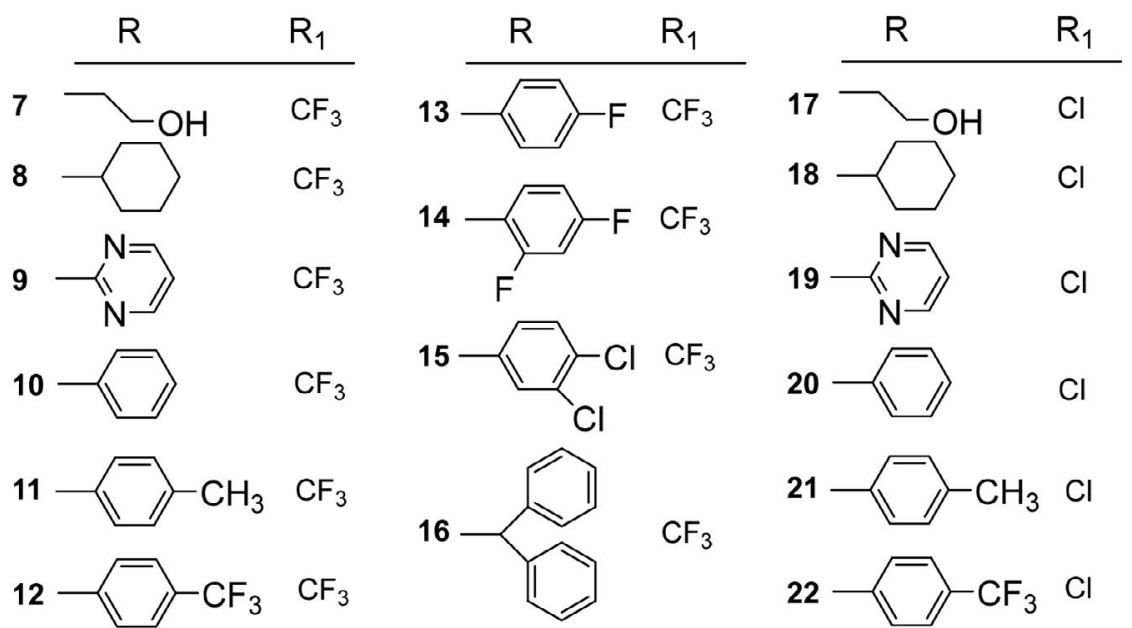<smiles>[R]CC(C)C</smiles><smiles></smiles><smiles>[123I]c1ncccn1</smiles><smiles>[Z4]c1ccc(F)cc1F</smiles>

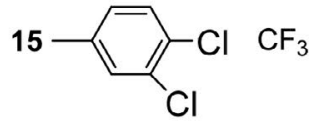<smiles>[18O]c1ccccc1</smiles><smiles>[13CH3]c1ccc(Cl)c(Cl)c1</smiles><smiles>c1ccc(C(c2ccccc2)c2ccccc2)cc1</smiles>

$\mathrm{CF}_{3}$<smiles>[Z17]c1ccc(C)cc1</smiles><smiles>[Z20]c1ccc(C(F)(F)Cl)cc1</smiles><smiles>O=C(c1ccccc1)c1ccccc1</smiles>

Scheme 1. (a) $\mathrm{SnCl}_{2} \cdot 2 \mathrm{H}_{2} \mathrm{O}$, EtOH; (b) 4-substituted benzylamine, $\mathrm{EtOH}, \mathrm{Et}_{3} \mathrm{~N}$; (c) $\mathrm{HC}(\mathrm{OEt})_{3}, \mathrm{pTSA}$; (d) 4-substituted piperazine, $\mathrm{Et}_{3} \mathrm{~N}$, EtOH 
Table 1. In vitro cytotoxicity of compounds $\mathbf{7 - 2 6}$ on different human cancer cell lines

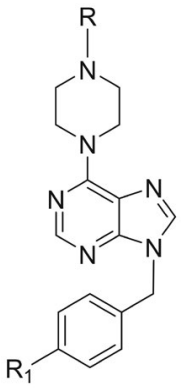

\begin{tabular}{|c|c|c|c|c|c|}
\hline \multirow[b]{2}{*}{ Compound } & \multicolumn{4}{|c|}{ Cancer cell lines, $\mathrm{IC}_{50}(\mu \mathrm{M})^{\mathrm{a}}$} & \multirow[b]{2}{*}{ MCF7 } \\
\hline & $\mathbf{R}$ & $\mathbf{R}_{1}$ & Huh7 & HCT116 & \\
\hline 7 & & $\mathrm{CF}_{3}$ & $18.25 \pm 0.55$ & $19.14 \pm 0.75$ & $17.83 \pm 0.56$ \\
\hline 8 & & $\mathrm{CF}_{3}$ & $7.86 \pm 0.04$ & $7.74 \pm 0.08$ & $6.51 \pm 0.52$ \\
\hline 9 & & $\mathrm{CF}_{3}$ & $9.6 \pm 0.6$ & $11.3 \pm 2.1$ & $17.8 \pm 0.2$ \\
\hline 10 & & $\mathrm{CF}_{3}$ & $0.86 \pm 0.19$ & $0.28 \pm 0.003$ & $0.16 \pm 0.037$ \\
\hline 11 & & $\mathrm{CF}_{3}$ & $<1.0$ & $<0.1$ & $<1.0$ \\
\hline 12 & & $\mathrm{CF}_{3}$ & $0.13 \pm 0.12$ & $0.42 \pm 0.08$ & 0.4 \\
\hline 13 & & $\mathrm{CF}_{3}$ & $1.54 \pm 0.10$ & $1.26 \pm 0.13$ & $1.12 \pm 0.16$ \\
\hline 14 & & $\mathrm{CF}_{3}$ & $5.05 \pm 0.52$ & $5.51 \pm 0.29$ & $4.24 \pm 1.17$ \\
\hline 15 & & $\mathrm{CF}_{3}$ & $0.6 \pm 0.1$ & $0.74 \pm 0.05$ & $<1.0$ \\
\hline 16 & & $\mathrm{CF}_{3}$ & $15.55 \pm 1.09$ & $12.97 \pm 1.11$ & $12.13 \pm 0.38$ \\
\hline 17 & & $\mathrm{Cl}$ & $21.8 \pm 2.7$ & $18.96 \pm 0.06$ & $21.8 \pm 4.4$ \\
\hline 18 & & $\mathrm{Cl}$ & $9.26 \pm 0.59$ & $8.87 \pm 0.35$ & $8.61 \pm 0.26$ \\
\hline 19 & & $\mathrm{Cl}$ & $38.0 \pm 5.1$ & $57.1 \pm 8.8$ & $100.9 \pm 28.0$ \\
\hline 20 & & $\mathrm{Cl}$ & $0.56 \pm 0.12$ & $0.26 \pm 0.17$ & $0.38 \pm 0.07$ \\
\hline 21 & & $\mathrm{Cl}$ & $<0.1$ & $0.26 \pm 0.35$ & $0.48 \pm 0.50$ \\
\hline 22 & & $\mathrm{Cl}$ & $0.08 \pm 0.06$ & $0.04 \pm 0.004$ & 0.05 \\
\hline 23 & & $\mathrm{Cl}$ & $0.57 \pm 0.12$ & $0.14 \pm 0.10$ & $2.80 \pm 3.22$ \\
\hline
\end{tabular}


24<smiles>Cc1ccc(F)cc1F</smiles>

25<smiles>Cc1ccc(Cl)c(Cl)c1</smiles>

26<smiles>CC(c1ccccc1)c1ccccc1</smiles>

CPT

5-FU
Cl

$\mathrm{Cl}$

$\mathrm{Cl}$
$9.38 \pm 0.65$

$0.31 \pm 0.10$

$20.1 \pm 6.8$

$<0.1$

$30.6 \pm 1.8$

$28.4 \pm 19.2$

$8.0 \pm 3.4$

$<0.1$

$0.9 \pm 0.7$
NI

$13.0 \pm 0.38$

$13.15 \pm 0.06$

$14.02 \pm 0.67$

$0.034 \pm 0.036$

$<0.1$

$4.1 \pm 0.3$

$3.5 \pm 0.7$
Fludarabine

Cladribine

${ }^{a} \mathrm{IC}_{50}$ values were calculated from the cell growth inhibition percentages obtained with 5 different concentrations (40, $20,10,5$, and $2.5 \mu \mathrm{M}$ ) of each molecule incubated for $72 \mathrm{~h}$. NI: no inhibition.

Table 2. $\mathrm{IC}_{50}$ values of $\mathbf{7 - 1 8}, \mathbf{2 0}, \mathbf{2 2 - 2 6}$ against hepatocellular carcinoma (HCC) cell lines Huh7, HepG2, MAHLAVU, FOCUS.

\begin{tabular}{ccccc}
\hline & \multicolumn{4}{c}{ HCC Cancer cell lines, IC $_{\mathbf{5 0}}(\boldsymbol{\mu M})^{\mathbf{a}}$} \\
Compound & Huh7 & HepG2 & Mahlavu & FOCUS \\
\hline $\mathbf{7}$ & $28.9 \pm 4.0$ & $25.2 \pm 4$ & NI & NI \\
$\mathbf{8}$ & $5.36 \pm 0.2$ & $6.4 \pm 0.5$ & $8.0 \pm 0.2$ & $6.4 \pm 0.6$ \\
$\mathbf{9}$ & $3.32 \pm 1.3$ & $4.3 \pm 0.6$ & $6.0 \pm 0.1$ & $7.2 \pm 1.7$ \\
$\mathbf{1 0}$ & $1.45 \pm 0.2$ & $1.4 \pm 0.2$ & $1.9 \pm 0.4$ & $1.5 \pm 0.5$ \\
$\mathbf{1 1}$ & $0.29 \pm 0.4$ & $<1.0$ & $\mathrm{NI}$ & $0.5 \pm 0.1$ \\
$\mathbf{1 2}$ & $0.13 \pm 0.1$ & $0.1 \pm 0.04$ & $<0.1$ & $<0.1$ \\
$\mathbf{1 3}$ & $2.13 \pm 0.1$ & $1.6 \pm 0.2$ & $2.3 \pm 0.3$ & $1.9 \pm 0.1$ \\
$\mathbf{1 4}$ & $5.48 \pm 0.2$ & $3.8 \pm 0.5$ & $4.8 \pm 0.2$ & $5.1 \pm 0.5$ \\
$\mathbf{1 5}$ & $0.24 \pm 0.1$ & $<0.1$ & $8.2 \pm 1.4$ & $1.4 \pm 0.3$ \\
$\mathbf{1 6}$ & $19.4 \pm 1.7$ & $32.3 \pm 23.9$ & $10.8 \pm 0.4$ & $11.6 \pm 0.4$ \\
$\mathbf{1 7}$ & $23.9 \pm 0.5$ & $69.4 \pm 25.7$ & $85.4 \pm 26.9$ & $83.3 \pm 14.2$ \\
$\mathbf{1 8}$ & $6.74 \pm 0.3$ & $7.3 \pm 1.3$ & $13.1 \pm 1.2$ & $9.1 \pm 0.9$ \\
$\mathbf{2 0}$ & $1.89 \pm 0.1$ & $1.5 \pm 0.2$ & $2.3 \pm 0.1$ & $0.2 \pm 0.1$ \\
$\mathbf{2 2}$ & $0.23 \pm 0.1$ & $<0.1$ & $<0.1$ & $<0.1$ \\
$\mathbf{2 3}$ & $2.33 \pm 0.2$ & $1.8 \pm 0.4$ & $3.2 \pm 0.2$ & $4.5 \pm 0.5$ \\
$\mathbf{2 4}$ & $2.22 \pm 0.4$ & $1.4 \pm 1.1$ & $11.1 \pm 1.9$ & $5.1 \pm 1.5$ \\
$\mathbf{2 5}$ & $<0.1$ & $<0.1$ & $5.6 \pm 0.1$ & $1.2 \pm 0.3$ \\
$\mathbf{2 6}$ & $16.4 \pm 1.7$ & $11.7 \pm 1.4$ & $12.1 \pm 0.6$ & $1 \pm 1$ \\
CPT & $<0.1$ & $<0.1$ & $<0.1$ & $<0.1$ \\
$\mathbf{5 - F U}$ & $30.6 \pm 1.8$ & $0.8 \pm 0.26$ & $10.0 \pm 1.8$ & $3.7 \pm 0.5$ \\
Fludarabine & $28.4 \pm 19.2$ & $17.0 \pm 5.9$ & $13.5 \pm 4.9$ & $13.7 \pm 1.2$ \\
Cladribine & $0.9 \pm 0.7$ & $0.4 \pm 0.1$ & $<0.1$ & $<0.1$ \\
\hline
\end{tabular}

${ }^{\mathrm{a}} \mathrm{IC}_{50}$ values were calculated from the cell growth inhibition percentages obtained with 5 different concentrations $(40,20,10,5$, and $2.5 \mu \mathrm{M})$ of each molecule incubated for $72 \mathrm{~h}$. NI: No inhibition

nyl and 4-methyl phenyl group bearing purin derivatives $(10,11,20,21)$ and these compounds had significantly higher bioactivity $\left(\mathrm{IC}_{50}<1.0 \mu \mathrm{M}\right)$ compared to 5 -FU, fludarabine, cladribine against Huh7 cell.
Within the tested purine analogs on HCT116 cell, compounds 11 and 22 showed superior cytotoxic activity ( $\mathrm{IC}_{50}<0.1$ and $0.04 \mu \mathrm{M}$, respectively) compared to 5 -FU ( $\left.\mathrm{IC}_{50} 4.1\right)$, fludarabine $\left(\mathrm{IC}_{50} 8.0 \mu \mathrm{M}\right)$, cladribine $\left(\mathrm{IC}_{50}<0.1\right.$ 
a) Huh7
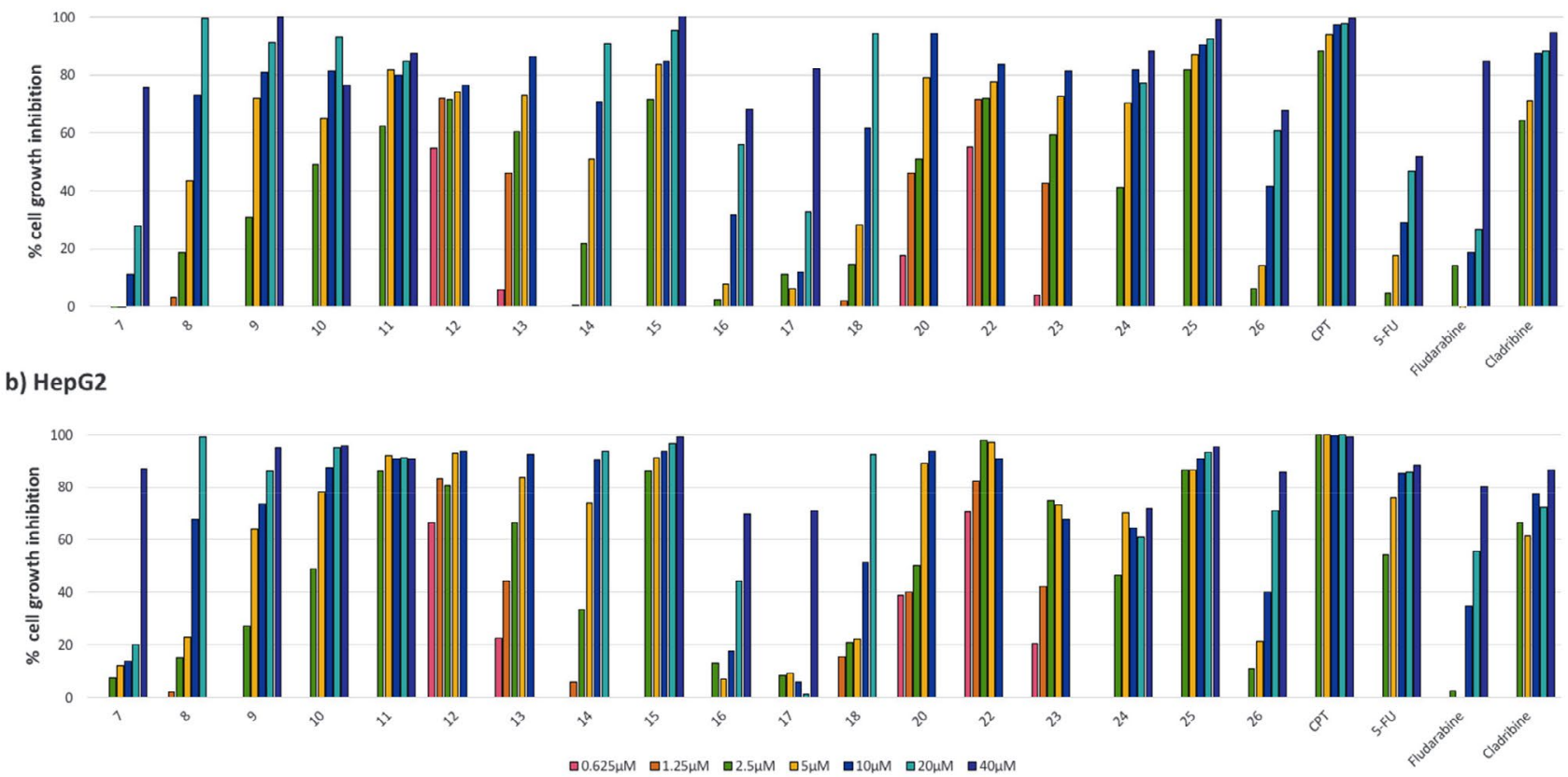

c) Mahlavu

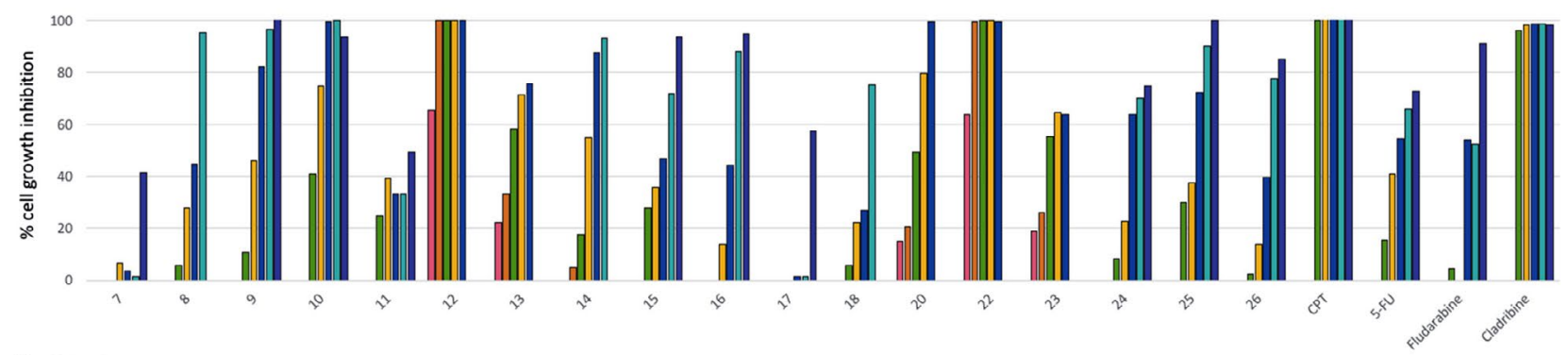

d) FOCUS

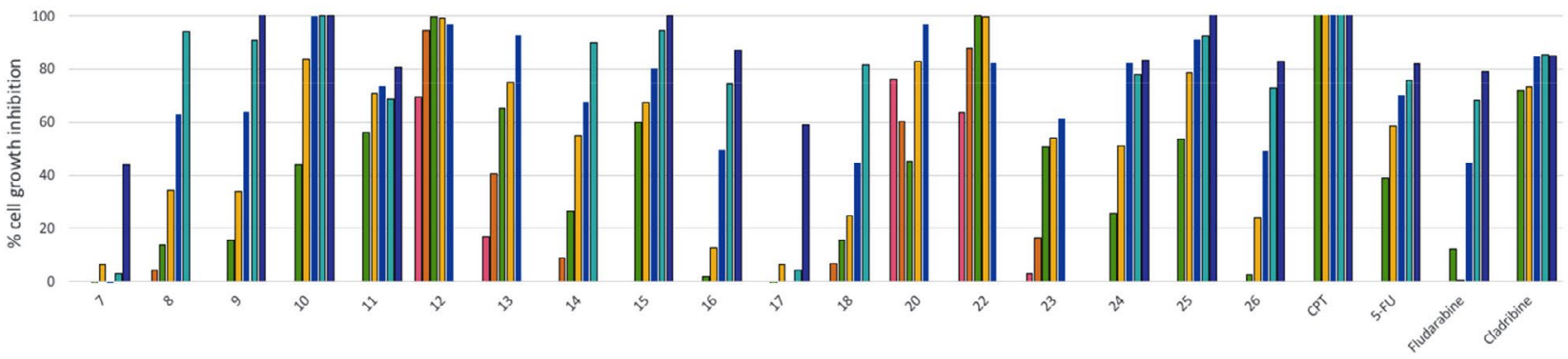

Figure 3. Percent cell death in the presence of most active compounds. Huh7, HepG2, Mahlavu and FOCUS cells were inoculated in 96-well plates. All molecules and their DMSO controls were administered to the cells in triplicate with five different concentrations: $40,20,10,5$, and 2.5 $\mu \mathrm{M}$. After $72 \mathrm{~h}$ of incubation, SRB assays were generated, and the cell death percentages were calculated in comparison with DMSO-treated wells.

$\mu \mathrm{M})$ and $\mathrm{CPT}\left(\mathrm{IC}_{50} 0.034 \mu \mathrm{M}\right)$. Furthermore, compounds $10,12,15,20,21,23$ had a better cytotoxic activity $\left(\mathrm{IC}_{50}<\right.$ $1.0 \mu \mathrm{M})$ than $5-\mathrm{FU}$ and fludarabine against HCT116 cell line.

Purine 22, one of the most cytotoxic molecules, displayed a significant $\mathrm{IC}_{50}$ value of $0.05 \mu \mathrm{M}$ comparable to $\mathrm{CPT}\left(\mathrm{IC}_{50}<0.1 \mu \mathrm{M}\right)$ on MCF7. Compound 22 also displayed better cytotoxic bioactivities on MCF7 cells with respect to 5-FU ( $\left.\mathrm{IC}_{50} 3.5 \mu \mathrm{M}\right)$ and known nucleoside drugs cladribine $\left(\mathrm{IC}_{50} 2.4 \mu \mathrm{M}\right)$ and fludarabine $\left(\mathrm{IC}_{50} 15.2 \mu \mathrm{M}\right)$, on MCF7 cells. In addition, the cytotoxic activity against MCF7 cell line of purines 7-26 was evaluated.

Significant bioactivity was also observed for compounds $10\left(\mathrm{IC}_{50} 0.16 \mu \mathrm{M}\right), \mathbf{1 2}\left(\mathrm{IC}_{50} 0.4 \mu \mathrm{M}\right), \mathbf{2 0}\left(\mathrm{IC}_{50} 0.38\right.$ $\mu \mathrm{M}), 21\left(\mathrm{IC}_{50} 0.48 \mu \mathrm{M}\right), \mathbf{1 1}, 15\left(\mathrm{IC}_{50}<1.0 \mu \mathrm{M}\right)$ on MCF7 cells.

We then screened the anticancer activity of the most potent purine analogs against further hepatocellular cancer 
a)

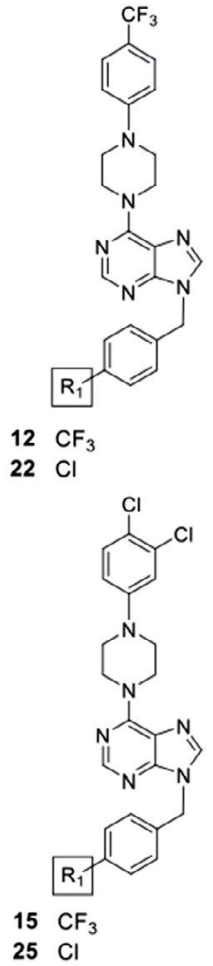

b)

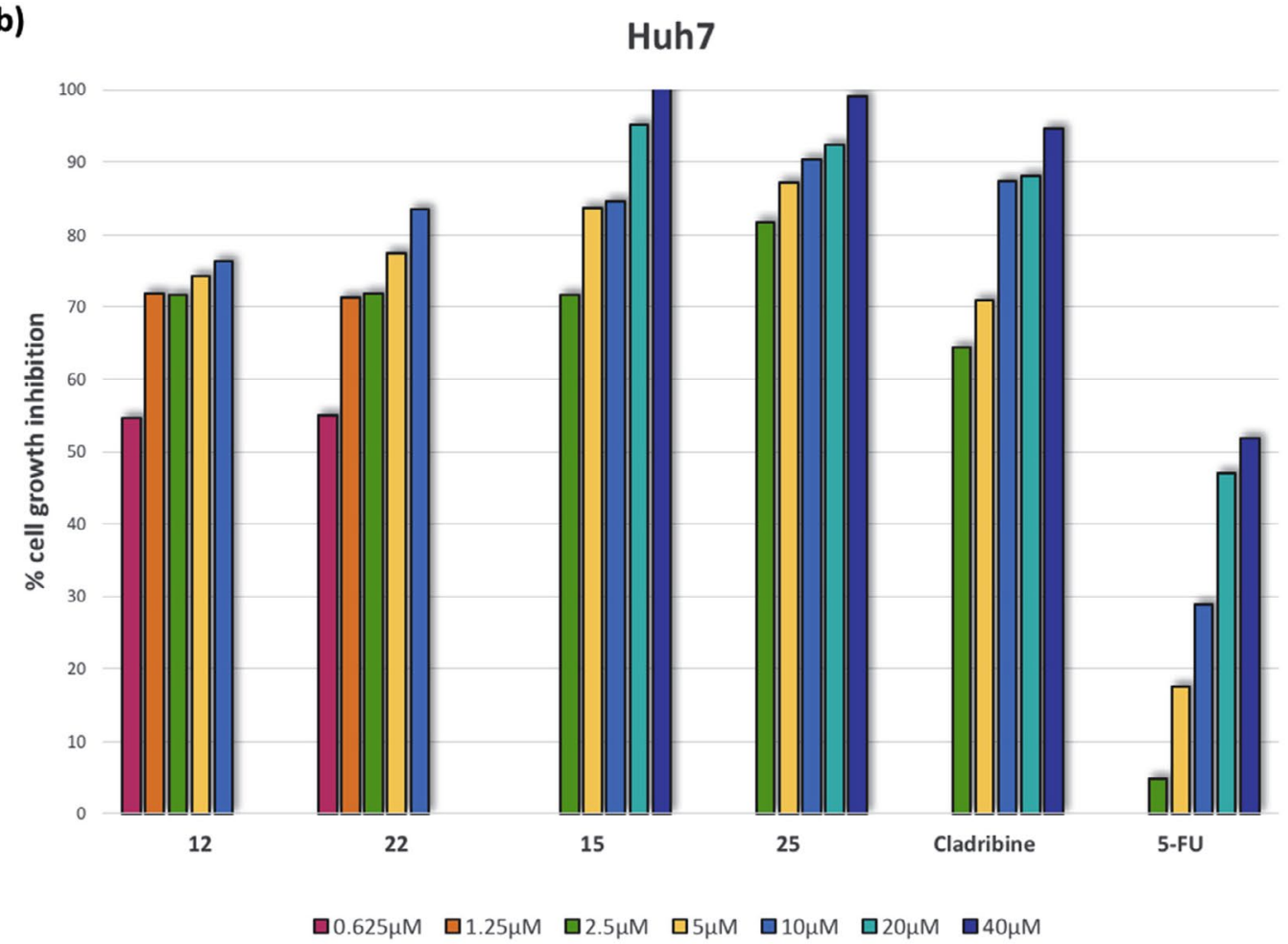

Figure 4. a) Chemical structures of the most active purine analogs 12, 22, 15 and 25 b) Percent cell death in the presence of most active compounds $(\mathbf{1 2}, 22,15$ and 25). Huh7 cells were inoculated in 96-well plates. All molecules and their DMSO controls were administered to the cells in triplicate with corresponding different concentrations: $0.625,1.25,2.5,5,10,20$, and $40 \mu \mathrm{M}$. After $72 \mathrm{~h}$ of incubation, SRB assays were generated, and the cell death percentages were calculated in comparison with DMSO-treated wells.

(HCC) cells lines (Table 2, Figure 3). We observed that the most important cell growth inhibition in the presence of 6-(4-(4-trifluoromethylphenyl)piperazine)-9-(4-trifluoromethylbenzyl)purine derivative $\mathbf{1 2}$ and its 9-(4-chlorobenzyl) analogue 22, with $\mathrm{IC}_{50}$ values of $<0.1-0.23 \mu \mathrm{M}$ against all the HCC cell lines. Compounds 12 and 22 also showed comparable cytotoxic effects with CPT and cladribine on these cell lines. Furthermore, $\mathbf{1 2}$ and $\mathbf{2 2}$ showed a better biological activity than the standard anticancer agents 5 -FU and fludarabine in HCC cell lines (Table 2). The 6-(4-(2,4-dichlorophenyl)piperazine analogs 15,25 were also very active $\left(\mathrm{IC}_{50}<0.1-0.24 \mu \mathrm{M}\right)$ against Huh7 and HepG2 cell lines.

\section{Conclusion}

We designed and synthesized twenty novel purine analogs 7-26 bearing substituted piperazine at the C-6, substituted benzyl group at the N-9, by the multistep reactions, starting from 4,6-dichloro-5-nitropyrimidine. The cytotoxic activities of the compounds were evaluated first in human liver (Huh7), breast (MCF7), colon (HCT116) and then in hepatocellular carcinoma cells (HCC): Huh7, HepG2, Mahlavu and FOCUS. Our results demonstrated that the 6-(trifluoromethylphenyl)piperazine analogs $\mathbf{1 2}$, 22 with $\mathrm{IC}_{50}$ values less than $0.5 \mu \mathrm{M}$ were promising molecules as cytotoxic agents on Huh7, MCF7 and HCT116 cancer cells. In order to investigate the use of potential cytotoxic agents on HCC, the bioactivity of the purine analogs was also tested in a panel of liver cancer cells. Molecules 12 and 22, that were synthesized as putative cytotoxic compounds, displayed the best anticancer bioactivities $\left(\mathrm{IC}_{50}<0.1-0.23 \mu \mathrm{M}\right)$ against $\mathrm{HCC}$ cell lines (Figure 4). These results indicate that these compounds can be considered as promising lead molecules for the development of potential anticancer agents.

\section{Acknowledgements}

This work was supported by the Scientific and Technological Research Council of Turkey-TUBITAK (TBAG109T987), the KANSIL-2016H121540 (Ministry of Development, Turkey).

\section{References}

1. M. E. Welsch, S. A. Snyder, B. R. Stockwell, Curr. Opin. Chem. Biol. 2010, 14, 347-361. DOI:10.1016/j.cbpa.2010.02.018

2. I. Moriguchi, Y. Kanada, Chem. Pharm. Bull. 1977, 25, 926935. DOI:10.1248/cpb.25.926

3. A. Brathe, G. Andresen, L. L. Gundersen, K. E. Malterud, F. Rise, Bioorg. Med. Chem. 2002, 10, 1581-1586.

DOI:10.1016/S0968-0896(01)00427-8 
4. A. Brathe, L. L. Gundersen, K. E. Malterud, F. Rise, Arch. Pharm. Chem. Life Sci. 2005, 338, 159-166.

DOI:10.1002/ardp.200400951

5. S. F. Laufer, D. M. Domeyer, T. R. Scior, W. Albrecht, D. R. J. Hauser, J. Med. Chem. 2005, 48, 710-722.

DOI:10.1021/jm0408767

6. J. A. Montgomery, K. Hewson, J. Med. Chem. 1968, 11, 48-52. DOI:10.1021/jm00307a010

7. G. Andersen, L. L. Gundersen, J. Nissen-Meyer, F. Rise, B. Spilsberg, Bioorg. Med. Chem. Lett. 2002, 12, 567-569. DOI:10.1016/S0960-894X(01)00803-4

8. J. F. Wang, L. R. Zhang, Z. J. Yang, L. H. Zhang, Bioorg. Med. Chem. 2004, 12, 1425-1429. DOI:10.1016/j.bmc.2004.01.005

9. M. Hocek, P. Naus, R. Pohl, I. Votruba, P. A. Furman, P. M. Tharnish, M. J. Otto, J. Med. Chem. 2005, 48, 5869-5873. DOI:10.1021/jm050335x

10. A. Kucukdumlu, M. Tuncbilek, E. B. Guven, R. C. Atalay, Acta Chim. Slov. 2017, 64, 621-632. DOI:10.17344/acsi.2017.3419

11. R. W. Sidwell, J. H. Huffman, G. P. Khare, L. B. Allen, J. T. Witkowski, R. K. Robins, Science. 1972, 177, 705-706.

DOI:10.1126/science.177.4050.705

12. E. De Clercq, Biochem. Pharmacol. 1987, 36, 2567-2575. DOI:10.1016/0006-2952(87)90533-8

13. E. De Clercq, Nucleosides Nucleotides. 1998, 17, 625-634. DOI:10.1080/07328319808005205

14. E. De Clercq, Antiviral Res. 2005, 67, 56-75. DOI:10.1016/j.antiviral.2005.05.001

15. B. Y. Kim, J. B. Ahn, H. W. Lee, S. K. Kang, J. H. Lee, J. S. Shin, S. K. Ahn, C. I. Hong, S. S. Yoon, Eur. J. Med. Chem. 2004, 39, 433-447. DOI:10.1016/j.ejmech.2004.03.001

16. G. Jin, C. C. N. Wu, R. I. Tawatao, M. Chan, D. A. Carson, H. B. Cottam, Bioorg. Med. Chem. Lett. 2006, 16, 4559-4563. DOI:10.1016/j.bmcl.2006.06.017

17. E. M. Peterson, J. Brownell, R. Vince, J. Med. Chem. 1992, 35, 3991-4000. DOI:10.1021/jm00100a003

18. A. Gangjee, A. Vasudevan, S. F. Queener, J. Med. Chem. 1997, 40, 3032-3039. DOI:10.1021/jm970271t

19. G. Gumina, C. K. Chu, Org. Lett. 2002, 4, 1147-1149. DOI: $10.1021 /$ ol025562x

20. F. Bordon-Pallier, N. Jullian, P. Ferrari, A. M. Girard, M. T. Bocquel, J. Biton, N. Bouquin, J. L. Haesslein, Biochim. Biophys. Acta. 2004, 1697, 211-223.

DOI:10.1016/j.bbapap.2003.11.025

21. P. R. Patel, C. Ramalingan, Y. T. Park, Bioorg. Med. Chem. Lett. 2007, 17, 6610-6614. DOI:10.1016/j.bmcl.2007.09.060

22. M. Tuncbilek, Z. Ates-Alagoz, N. Altanlar, A. Karayel, S. Ozbey, Bioorg. Med. Chem. 2009, 17, 1693-1700.

DOI:10.1016/j.bmc.2008.12.050

23. J. G. Kuhn, Ann Pharmacother. 2001, 35, 217-227. DOI:10.1345/aph.10096

24. C. M. Galmarini, J. R. Mackey, C. Dumontet, Lancet Oncol. 2002, 3, 415-424. DOI:10.1016/S1470-2045(02)00788-X

25. D. Sampath, V. A. Rao, W. Plunkett, Oncogene. 2003, 22, 9063-9074. DOI:10.1038/sj.onc.1207229

26. C. M. Galmarini, F. Popowycz, B. Joseph, Curr. Med. Chem. 2008, 15, 1072-1082. DOI:10.2174/092986708784221449
27. G. Escherich, S. Richards, L. J. Stork, A. J. Vora, Leukemia. 2011, 25, 95-959. DOI:10.1038/leu.2011.37

28. P. N. Munshi, M. Lubin, J. R. Bertino, Oncologist. 2014, 19, 760-765. DOI:10.1634/theoncologist.2014-0178

29. S. A. Johnson, W. Thomas, Hematol. Oncol. 2000, 18, 141-153. DOI:10.1002/1099-1069(200012)18:4<141::AID-HON666 $>3.0 . \mathrm{CO} ; 2-\#$

30. S. A. Johnson, Expert Opin. Pharmacother. 2001, 2, 929-943.

31. W. B. Parker, J. A. $3^{\text {rd }}$ Secrist, W. R. Waud, Curr. Opin. Invest. Drugs. 2004, 5, 592-596.

32. E. Lech-Maranda, A. Korycka, T. Robak, Mini-Rev Med Chem. 2006, 6, 575-581. DOI:10.2174/138955706776876212

33. M. S. Ricci, W. X. Zong, Oncologist. 2006, 11, 342-357. DOI:10.1634/theoncologist.11-4-342

34. M. Collado, M. Serrano, Nature Rev. Cancer. 2006, 6, 472-476. DOI: $10.1038 / \mathrm{nrc} 1884$

35. C. Nardella, J. G. Clohessy, A. Alimonti, P. P. Pandolfi, Nature Rev. Cancer. 2011, 11, 503-511. DOI:10.1038/nrc3057

36. J. L. Haesslein, N. Jullian, Curr. Topics Med. Chem. 2002, 2, 1037-1050. DOI:10.2174/1568026023393291

37. W. F. De Azevedo, S. Leclerc, L. Meijer, L. Havlicek, M. Strnad, S. H. Kim, Eur. J. Biochem. 1997, 243, 518-526. DOI:10.1111/j.1432-1033.1997.0518a.x

38. Y. T. Chang, N. S. Gray, G. R. Rosania, D. P. Sutherlin, S. Kwon, T. C. Norman, R. Sarohia, M. Leost, L. Meijer, P. G. Schultz, Chem. and Biol. 1999, 6, 361-375. DOI:10.1016/S1074-5521(99)80048-9

39.K. Zurbonsen, A. Michel, P. A. Bonnet, L. Gannoun-Zaki, M. N. Mathieu, C. Chevillard, Eur. J. Pharmacol. 1997, 320, 215221. DOI:10.1016/S0014-2999(96)00890-4

40. M. F. Brana, M. Cacho, M. L. Garcia, E. P. Mayoral, B. Lopez, B. De Pascual-Teresa, A. Ramos, N. Acero, F. Llinares, D. Munoz-Mingarro, O. Lozach, L. Meijer, J. Med. Chem. 2005, 48, 6843-6854. DOI:10.1021/jm058013g

41. C. Jaramillo, J. E. Diego, C. Hamdouchi, E. Collins, H. Keyser, C. Sanchez-Martınez, M. Prado, B. Norman, H. B. Brooks, S. A. Watkins, C. D. Spencer, J. A. Dempsey, B. D. Anderson, R. M. Campbell, T. Leggett, B. Patel, R. M. Schultz, J. Espinosa, M. Vieth, F. M. Zhang D. E. Timm, Bioorg. Med. Chem. Lett. 2004, 14, 6095-6099. DOI:10.1016/j.bmcl.2004.09.053

42. R. M. Mohareb, A. A. Mohamed, A. E. M. Abdallah, Acta Chim. Slov. 2016, 63, 227-240. DOI:10.17344/acsi.2015.1668

43. R. M. Mohareb, N. Y. M. Abdo, F. O. Al-Farouk, Acta Chim. Slov. 2017, 64, 117-128 117. DOI:10.17344/acsi.2016.2920

44. A. Gaagjee, X. Lin, R. L. Kisliuk, J. J. McGuire, J. Med. Chem. 2005, 48, 7215-7222.

45. S. Schenone, O. Bruno, A. Ranise, F. Bondavalli, C. Brullo, P. Fossa, L. Mosti, G. Menozzi, F. Carraro, A. Naldini, C. Bernini, F. Manetti, M. Botta, Bioorg. Med. Chem. Lett. 2004, 14, 2511-2517.

46. J. A. Markwalder, M. R. Arnone, P. A. Benfield, M. Biosdir, M. Boisclair, C. R. Burton, C. H. Chang, S. S. Cox, P. M. Czerniak, C. L. Dean, D. Doleniak, R. Grafstrom, B. A. Harrison, R. F. Kaltenbach, D. A. Nugiel, K. A. Rossi, S. R. Sherk, L. M. Sisk, P. Stouten, G. L. Trainor, P. Worland, S. P. Seitz, J. Med. Chem. 2004, 47, 5894-5911. DOI:10.1021/jm020455u 
47. E. H. El-Sayed1, A. A. Fadda, Acta Chim. Slov. 2018, 65, 853864. DOI:10.17344/acsi.2018.4506

48. L. Havlicek, K. Fuksova, V. Krystof, M. Orsag, B. Vojtesek, M. Strnad, Bioorg. Med. Chem. 2005, 13, 5399-5407.

DOI:10.1016/j.bmc.2005.06.007

49. S. Botros, O. M. Khalil, M. M. Kamel, Y. S. El-Dash, Acta Chim. Slov. 2017, 64, 102-116. DOI:10.17344/acsi.2016.2901

50. M. A. Biamonte, R. Van de Water, J. W. Arndt, R. H. Scannevin, D. Perret, W. C. Lee, J. Med. Chem. 2010, 53, 3-17.

DOI:10.1021/jm9004708
51. M. Tuncbilek, E. Bilget Guven, T. Onder, R. Cetin Atalay, J. Med. Chem. 2012, 55, 3058-3065.

DOI:10.1021/jm3001532

52. Z. Demir, E. B. Guven, S. Ozbey, C. Kazak, R. C. Atalay, M. Tuncbilek, Eur. J. Med. Chem. 2015, 89, 701-720. DOI:10.1016/j.ejmech.2014.10.080

53. D. L. Romero, C. E. Masse, S. Robinson, J. R. Greenwood, G. Harriman, PCT Int Appl WO 2015/048281 Al. 2015, 1-168

54. A. K. Bakkestuen, L. L. Gundersen, B. T. Utenova, J. Med. Chem. 2005, 48, 2710-2723. DOI:10.1021/jm0408924

\section{Povzetek}

Načrtovali in izvedli smo sintezo serije novih 6,9-disubstituiranih purinskih analogov, ki na položaju C-6 vsebujejo 4-substituiran piperazin, na položaju N-9 pa 4-substituiran benzilni fragment.Vse pripravljene spojine (7-26) smo in vitro testirali za morebitno protirakavo aktivnost na Huh7 celicah jeter, HCT116 celicah debelega črevesa in MCF7 pljučnih celicah rakavih celičnih linij. Študije citotoksične bioaktivnosti so pokazale, da so vse spojine, z izjemo 19, obetavno citotoksične $\mathrm{z} \mathrm{IC}_{50}$ vrednostmi med 0.05-21.8 $\mu \mathrm{M}$ proti Huh7, HCT116 in MCF7 celičnim linijam. Med vsemi pripravljenimi purinskimi analogi sta dva (12 in 22) izkazala posebej odlično citotoksično aktivnost in sicer $\mathrm{IC}_{50} 0.08$ $0.13 \mu \mathrm{M}$ na Huh7 celicah, kar je primerljivo s kamptotecinom (CPT) in boljše od kladribina, fludarabina in 5-FU. Nato smo raziskali še citotoksičnost najbolj aktivnih purinskih analogov na hepatocelične (HCC) rakave celice ter ugotovili, da spojini 6-(4-(4-trifluorometilfenil)piperazin (12) in 6-(4-(3,4-diklorofenil)piperazin (25) izkazujeta zelo obetavne $\mathrm{IC}_{50}$ vrednosti $\left(\mathrm{IC}_{50}<0.1-0.13 \mu \mathrm{M}\right)$, ki so primerljive $\mathrm{z}$ vrednostmi za CPT in boljše kot je citotoksična bioaktivnost 5-FU, kladribina in fludarabina na HCC celice (Huh7 in HepG2).

Except when otherwise noted, articles in this journal are published under the terms and conditions of the Creative Commons Attribution 4.0 International License 